\title{
Experimental and theoretical investigations of ionization/dissociation of cyclopentanone molecule in a femtosecond laser field
}

\author{
Qiaoqiao Wang, ${ }^{1}$ Di Wu, ${ }^{1}$ Mingxing Jin, ${ }^{1}$ Fuchun Liu, ${ }^{1}$ Feifei Hu, ${ }^{1}$ Xihui Cheng, ${ }^{1}$ \\ Hang Liu, ${ }^{1}$ Zhan Hu, ${ }^{1}$ Dajun Ding, ${ }^{1, a)}$ H. Mineo, ${ }^{2}$ Y. A. Dyakov, ${ }^{3}$ A. M. Mebel, ${ }^{4, b}$ \\ S. D. Chao, ${ }^{2}$ and S. H. Lin ${ }^{3,5}$ \\ ${ }^{1}$ Institute of Atomic and Molecular Physics, Jilin University, Changchun 130012, \\ People's Republic of China \\ ${ }^{2}$ Institute of Applied Mechanics, National Taiwan University, Taipei 106, Taiwan \\ ${ }^{3}$ Institute of Atomic and Molecular Sciences, Academia Sinica, Taipei 106, Taiwan \\ ${ }^{4}$ Department of Chemistry and Biochemistry, Florida International University, $11200 \mathrm{SW}$ 8th Street, Miami, \\ Florida 33199, USA \\ ${ }^{5}$ Department of Applied Chemistry, National Chiao-Tung University, Hsin-Chu 300, Taiwan
}

(Received 25 June 2008; accepted 1 October 2008; published online 24 November 2008)

\begin{abstract}
The ionization/dissociation mechanism of cyclopentanone has been experimentally investigated in molecular beam by irradiating with intense 394 and $788 \mathrm{~nm}$ laser fields with pulse duration of $90 \mathrm{fs}$. The range of laser intensities varied from $3 \times 10^{13}$ to $4 \times 10^{14} \mathrm{~W} / \mathrm{cm}^{2}$. For both wavelengths, the singly charged parent ion is observable while the doubly charged one cannot be found easily, although the fragmentation pattern supports its presence. Meanwhile, the extent of fragmentation at $788 \mathrm{~nm}$ is less than that in the $394 \mathrm{~nm}$ case. We quantitatively analyze the ionization processes of cyclopentanone in intense femtosecond laser by comparing the calculation results of ionization rate constants obtained from Ammosov-Delone-Krainov, Keldysh, and Keldysh-Faisal-Reiss (KFR) theories based on hydrogenlike atom model. We also compare the experimental and theoretical results; the generalized KFR theory is found to be useful in predicting the ionization yields of singly and doubly charged cyclopentanone ion. To interpret the dissociation patterns of the cyclopentanone ions, we have used the Rice-Ramsperger-Kassel-Marcus theory with the potential surfaces obtained from the ab initio quantum chemical calculations. () 2008 American Institute of Physics.
\end{abstract}

[DOI: $10.1063 / 1.3006028]$

\section{INTRODUCTION}

The photoionization and dissociation processes of polyatomic molecules induced by intense femtosecond laser pulses with an intensity range of $10^{13}-10^{16} \mathrm{~W} / \mathrm{cm}^{2}$ have been extensively reported recently. ${ }^{1-9}$ However, the photoionization mechanism of the molecules is still ambiguous, and the understanding of fragmentations of the molecules (neutral or charged) is even less clear. Cycloketones are well known to have flexible structures with ring puckering or twisting motion, ${ }^{10}$ and their spectra have been investigated by numerous methods. Furuya et al. ${ }^{11}$ explored the triplet states of cyclopentanone and cyclohexanone using lowenergy electron impact at electron energy of $5 \mathrm{eV}$ and assigned five triplet bands together with four singlet bands. Baba et al. ${ }^{12}$ reported the resonance enhanced multiphoton ionization (REMPI) mass spectra of acetone and cycloketones by using UV excimer laser $(248 \mathrm{~nm}$ or $193 \mathrm{~nm}$ ) with $10 \mathrm{~ns}$ pulse duration, which resonances with the intermediate state, ${ }^{1}\left(n, \pi^{*}\right)$ or ${ }^{1}(n, 3 s)$. They proposed that the fragment ions of smaller ketones were originated from the sequential photoionization of the fragments containing carbonyl group after photodissociation. However, as the molecular size increased, the generation of fragment ions through direct two-

\footnotetext{
${ }^{a)}$ Electronic mail: dajund@jlu.edu.cn.

b) Electronic mail: mebela@fiu.edu.
}

photon excitation became more important. Moreover, the two-photon excitations of the $3 s, 3 p$, and $3 d$ Rydberg transitions in these molecules were recorded by REMPI. ${ }^{10,13,14} \mathrm{Ac}-$ cording to these studies, different vibronic modes have been identified and the photodissociation mechanism has been proposed. Recently, cycloketones including cyclopentanone were investigated by several groups making use of femtosecond pulsed laser. Zewail and co-workers ${ }^{15,16}$ extensively studied the molecular reaction dynamics of cycloketones irradiated by $60 \mathrm{fs}$ pulsed laser, by using a $310 \mathrm{~nm}$ pump and $620 \mathrm{~nm}$ probe combined with a time-of-flight mass spectrometer (TOF-MS). The evolutions of the reaction intermediates involving diradicals provided a real-time picture of the nuclear motions and structural changes during the reaction. Wu et al. ${ }^{17}$ studied the dissociation dynamics of cyclopentanone and cyclohexanone by means of a femtosecond laser with 50 fs pulse duration and $800 \mathrm{~nm}$ wavelength. They concluded that the fragmentation of the parent ions increases with the laser intensity and molecular size. In our previous study, ${ }^{9}$ we compared the experimental observations in a $90 \mathrm{fs}$ laser at 394 or $788 \mathrm{~nm}$ with the time-dependent density functional theory calculated molecular absorption spectra, and illustrated that the yields of cycloketones molecular ions were affected by the characteristics of the cation absorption at the laser wavelength.

In this paper, we discuss the ionization/dissociation pro- 
cesses of the cyclopentanone molecule in femtosecond intense laser field. Experimentally, we use 394 and $788 \mathrm{~nm}$ fs laser pulses to irradiate cyclopentanone, and observe the ion signals with TOF-MS. Theoretically, through a quantitative calculation of the ionization rate constants for the molecule, treating it as a hydrogenlike atom by different methods such as Ammosov-Delone-Krainov (ADK), Keldysh, and Keldysh-Faisal-Reiss (KFR) theories, we point out that both ADK and Keldysh theories overestimate the rate constants. As for a real molecular system, the structural characteristics of the molecule, including its vibrational structure, should be considered; therefore, the generalized KFR theory combined with the molecular orbital (MO) theory is chosen to calculate the ionization rate constants of cyclopentanone. A consistency of the results between the experimental observations and the theoretical model calculation is achieved. A qualitative understanding of the femtosecond dissociation of cyclopentanone has been attempted by using Rice-RomspergerKassel-Marous (RRKM) theory based on the $a b$ initio calculations.

\section{EXPERIMENTAL DETAILS}

\section{A. Experimental setup}

The experimental setup used for the femtosecond laser ionization/dissociation study has been described elsewhere. ${ }^{9,18}$ Briefly, a chirped pulse amplified Ti:sapphire laser (Spectra-Physics) is employed. This system produces a $90 \mathrm{fs}$, linearly polarized laser beam with a repetition rate of $10 \mathrm{~Hz}$ and wavelength centered at $788 \mathrm{~nm}$. The laser beam is frequency doubled by a beta barium borate crystal to give a $394 \mathrm{~nm}$ linearly polarized laser beam. Variable attenuation of the beam intensity is achieved using a rotatable half-wave plate followed by a Glan-Taylor prism. This method can also ensure that the direction of laser polarization is parallel or perpendicular to the flight axis of the TOF always during changing the beam intensity. The laser beam enters the vacuum chamber through a quartz window and is focused by a quartz plano-convex lens $(f=350 \mathrm{~mm})$ so as to achieve laser intensities in the range of $10^{13}-10^{14} \mathrm{~W} / \mathrm{cm}^{2}$, which are estimated by

$$
I\left(\mathrm{~W} / \mathrm{cm}^{2}\right)=\frac{E(\mathrm{~J})}{\Gamma(\mathrm{s}) A\left(\mathrm{~cm}^{2}\right)}
$$

from the measured pulse energy $E$, the pulse width $\Gamma$, and the focus spot area $A$ obtained from the radius $r$ of this spot as the $1 / e^{2}$ points of a Gaussian profile,

$$
r=\frac{2 f \lambda}{\pi D},
$$

where $f$ is the mirror focal length, $\lambda$ is the wavelength, and $D$ is the prefocused beam diameter. In general, with a $350 \mathrm{~mm}$ focus lens, $90 \mathrm{fs}$ pulse duration, $394 \mathrm{~nm}$ wavelength, and $1 \mathrm{~mJ}$ pulse energy, the beam intensity will be a few times of $10^{14} \mathrm{~W} / \mathrm{cm}^{2}$.

Commercial cyclopentanone sample (Aldrich Co. Ltd., $99 \%$ purity) is used without further purification. It is expanded into a vacuum chamber in a background pressure of $10^{-7}$ Torr through a pulsed valve with $400 \mu$ s duration. A

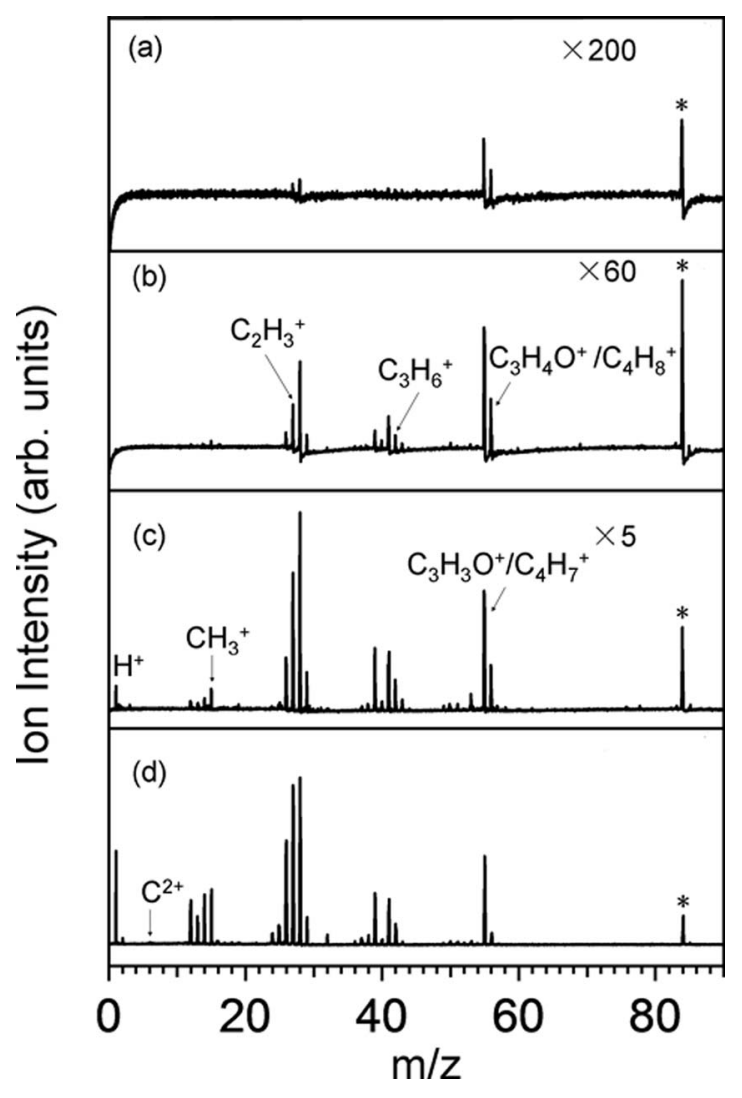

FIG. 1. Mass spectra of cyclopentanone interacted with 90 fs laser pulses at $394 \mathrm{~nm}$ for four different intensities: (a) $3.3 \times 10^{13} \mathrm{~W} / \mathrm{cm}^{2}$, (b) 7.0 $\times 10^{13} \mathrm{~W} / \mathrm{cm}^{2}$, (c) $1.5 \times 10^{14} \mathrm{~W} / \mathrm{cm}^{2}$, and (d) $3.9 \times 10^{14} \mathrm{~W} / \mathrm{cm}^{2}$. The asterisk denotes the parent ion.

linear TOF-MS is operated on Wiley-McLaren focusing condition. The produced ions are introduced into a $90 \mathrm{~cm}$ fieldfree region after two-step acceleration and are detected by a pair of microchannel plates. A slit with $0.5 \mathrm{~mm}$ width is mounted in front of the flight tube for ensuring that only the ions produced in the center portion of the laser focus volume can enter the drift tube. By connecting the ion detector output through a fast preamplifier to a digital storage oscilloscope (Tektronix TDS 3054B), mass spectra are accumulated and averaged over 512 laser shots normally and then transferred into a computer. Typically, the mass resolution at $m / e=100$ is $M / \Delta M=1000$.

\section{B. TOF-MS observation of cyclopentanone}

The mass spectra of cyclopentanone for two wavelengths $(394 \mathrm{~nm}, 788 \mathrm{~nm})$ are shown in Figs. 1 and 2, respectively. They are obtained under four different laser intensities, covering from $3 \times 10^{13}$ to $4 \times 10^{14} \mathrm{~W} / \mathrm{cm}^{2}$. In the case of $788 \mathrm{~nm}$ irradiation with low laser intensities, the singly charged cyclopentanone parent ion is dominant, being accompanied by weak fragment ions. For the $394 \mathrm{~nm}$ case, however, although singly charged parent ion is predominant at low laser intensities, the fragment ions are more abundant than at $788 \mathrm{~nm}$. Moreover, with increasing laser intensity, smaller fragment ions appear and increase for both wavelengths. It should be noted that in all mass spectra, the singly charged parent ion is clearly seen while the doubly charged parent ions cannot be assigned definitely because the peak at 


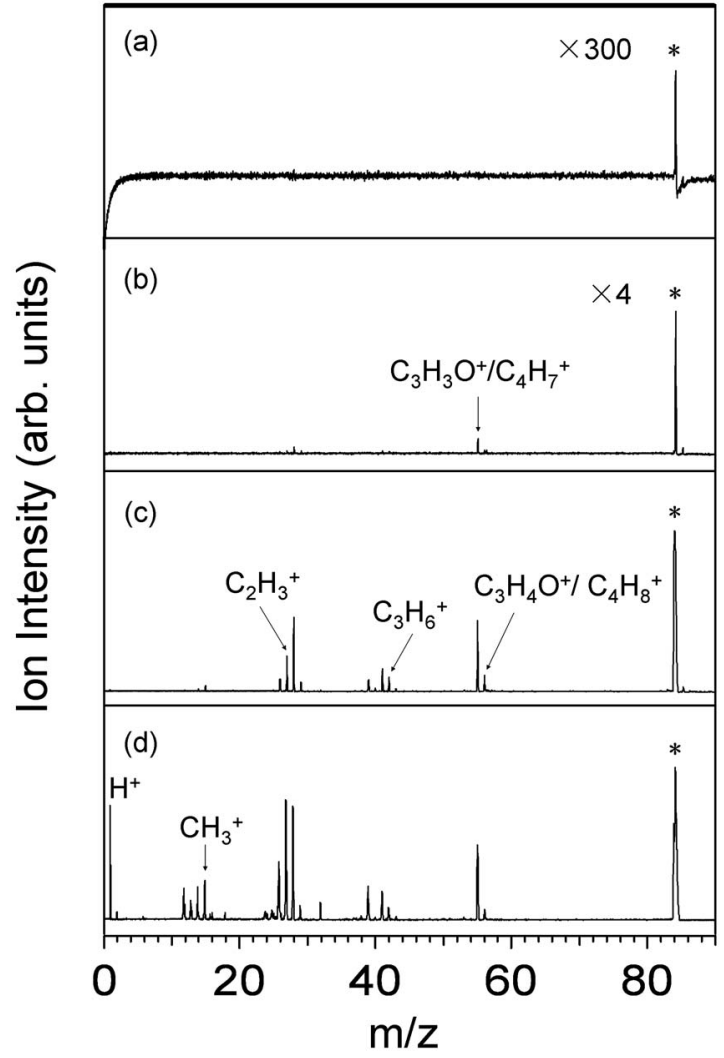

FIG. 2. Mass spectra of cyclopentanone interacted with 90 fs laser pulses at $788 \mathrm{~nm}$ for four different intensities: (a) $3.4 \times 10^{13} \mathrm{~W} / \mathrm{cm}^{2}$, (b) 7.0 $\times 10^{13} \mathrm{~W} / \mathrm{cm}^{2}$, (c) $1.5 \times 10^{14} \mathrm{~W} / \mathrm{cm}^{2}$, and (d) $4.0 \times 10^{14} \mathrm{~W} / \mathrm{cm}^{2}$. The asterisk denotes the parent ion.

$m / z=42$ may be attributed to a fragment ion with the same mass-to-charge ratio (such as $\mathrm{C}_{3} \mathrm{H}_{6}^{+}$). This result is different from the observation of other aromatic molecules such as toluene and benzene under similar experimental conditions, ${ }^{19}$ in which for laser intensities $I>2 \times 10^{14} \mathrm{~W} / \mathrm{cm}^{2}$ further increase of fragment ions and multiply charged parent ions can be observed, and the molecular aromaticity favors generation of the multiply charged intact ion regardless of the nature of the highest occupied molecular orbital (HOMO).

The ion intensities of the parent ion and two fragment ions, $m / z=55$ and $m / z=42$, as a function of laser intensity from $2 \times 10^{13}$ to $4 \times 10^{14} \mathrm{~W} / \mathrm{cm}^{2}$ are shown in Figs. 3 and 4 for 394 and $788 \mathrm{~nm}$, respectively, in a log-log form. With regard to each wavelength, this laser intensity dependence of the ion yield is determined by measuring the ion peak area under the curve in the mass spectrum. For cyclopentanone, since its ionization potential is $9.28 \mathrm{eV},{ }^{20}$ the minimum photon number of $394 \mathrm{~nm}$ necessary for ionization is 3 while that of $788 \mathrm{~nm}$ is 6 . It is noted that the measured dependence cannot be fitted well by only one straight line in a log-log scale for the whole laser intensity range used. Roughly, we can explain the experimental results within the frame of the MPI mechanism in a certain laser intensity range. At $394 \mathrm{~nm}$ with intensity from $4 \times 10^{13}$ to $1 \times 10^{14} \mathrm{~W} / \mathrm{cm}^{2}$, the slope for the yield of the parent ion is 2.9 , which is close to the photon number for ionization mentioned above. The $\mathrm{m} / \mathrm{z}$ $=55$ peak exhibits a photon number of 3.1, implying that the photodissociation of this fragment may be a rate-limiting (or bottleneck) process and the meaning of this slope also presents the order of photoionization process. The yield of $m / z=42$ ion has a slope of 4.2 , suggesting that this ion is produced through a process with a higher order. On the other hand, for $788 \mathrm{~nm}$, the slope of the parent ion yields in the intensity region below $9 \times 10^{13} \mathrm{~W} / \mathrm{cm}^{2}$ is 6.2 . Similar to the results obtained for $394 \mathrm{~nm}$, the slope of $m / z=55$ fragment ion is the same as that of the parent ion. On the contrary, the slope of fragment ion with $\mathrm{m} / z=42$ is less than that of the parent ion. This may be owing to some effects induced by intense femtosecond laser field such as so-called field assistant dissociation (FAD) and requires further investigation.

\section{THEORETICAL TREATMENTS}

\section{A. Theoretical model}

There are many theoretical methods used to treat for the ionization processes of polyatomic molecules, such as $\mathrm{ADK},{ }^{21-23}$ Keldysh, ${ }^{24-26}$ KFR theory, ${ }^{24,27,28}$ and so on. In the present work, we firstly use these theories to calculate ionization rate constants of cyclopentanone and cyclopentanone ion based on a hydrogenlike atom approach. By comparison, according to the rate limitation of ionized electron, we ob-
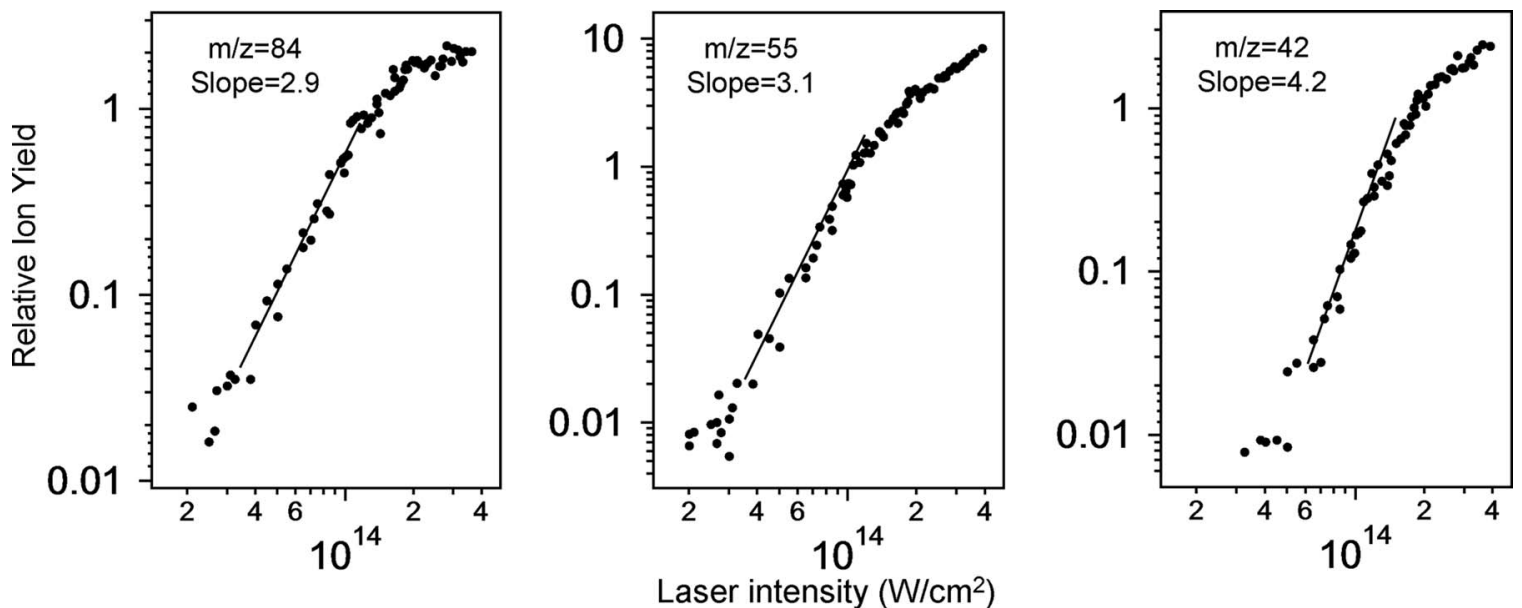

FIG. 3. Relative ion yields of parent and main fragments ions as a function of laser intensity. The wavelength is $394 \mathrm{~nm}$. A linear fit through the data points is shown as the solid line. Notice the approach to saturation of the parent ion signal for intensities in the region of $10^{14} \mathrm{~W} / \mathrm{cm}^{2}$. 

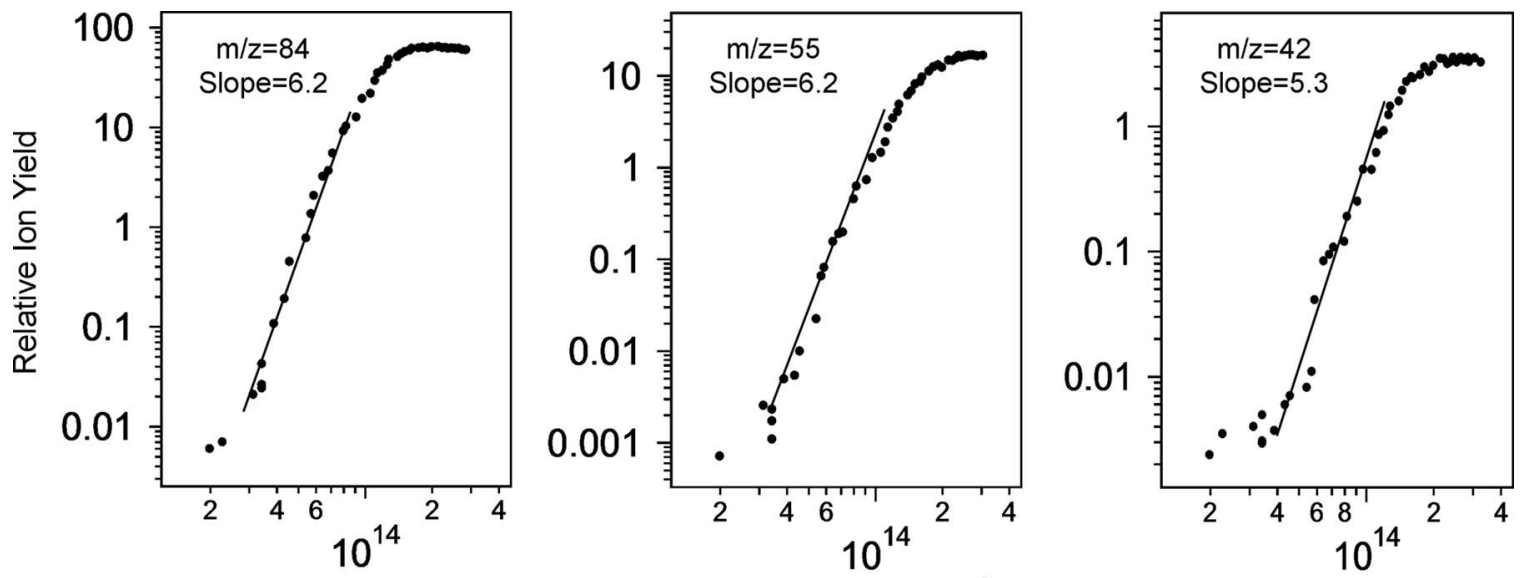

Laser intensity $\left(\mathrm{W} / \mathrm{cm}^{2}\right)$

FIG. 4. Relative ion yields of parent and main fragments ions as a function of laser intensity. The wavelength is $788 \mathrm{~nm}$. In the same way, a linear fit through the data points is shown as the solid line. The saturation of the parent ion signal for intensities occurs in the same region of $10^{14} \mathrm{~W} / \mathrm{cm}^{2}$.

serve that ADK theory and Keldysh theory overestimate the rate constants in the intensity range of $10^{13}-10^{15} \mathrm{~W} / \mathrm{cm}^{2}$. Therefore, the generalized KFR theory is chosen finally.

In detail, generalized KFR theory ${ }^{29}$ is originally proposed by Faisal ${ }^{30}$ based on the Keldysh theory and developed with the $S$-matrix formalism by Reiss ${ }^{31}$ by combining the MO theory and the Born-Oppenheimer (BO) approximation. We assume that the ground electronic state of molecule (or molecular cation) is well described in terms of molecular orbitals and obtained from ab initio calculation. For the ionized state, the ionized electron wave function is described by the Volkov continuum state,

$$
\psi_{\vec{p}}(\vec{r}, t)=\exp \left[i\left(\vec{p} \cdot \vec{r}-\frac{1}{2 m_{e}} \int_{-\infty}^{t} d t^{\prime}\left(\vec{p}-e \vec{A}\left(t^{\prime}\right)\right)^{2}\right)\right]
$$

where $e(=-1)$ is the charge of electron, $\vec{p}$ is the momentum of the ionized electron, and under the dipole approximation the vector potential $\vec{A}(t)$ is given by $\vec{A}(t)=-\vec{F} \sin (\omega t) / \omega$ for the linearly polarized laser field $\vec{F}(t)=\vec{F} \cos (\omega t)$.

Then, the total electronic wave function of the molecule (or molecular cation) is expressed as

$$
\begin{aligned}
\Psi_{M}\left(\vec{r}_{1}, \ldots, \vec{r}_{N_{e}}, t\right)= & \Psi_{g}\left(\vec{r}_{1}, \ldots, \vec{r}_{N_{e}}, t\right) \\
& +\int \frac{d^{3} p}{(2 \pi)^{3}} c_{\vec{p}}(t) \Psi_{l, \vec{p}}\left(\vec{r}_{1}, \ldots, \vec{r}_{N_{e}}, t\right),
\end{aligned}
$$

where $N_{e}$ is the number of electrons and

$$
\begin{aligned}
c_{\vec{p}}(t)= & -i \int_{-\infty}^{t} d t^{\prime}\left\langle\Psi_{l, \vec{p}}\left(\vec{p}_{1}, \ldots, \vec{r}_{N_{e}}, t\right)\right. \\
& \left.\times\left|\hat{V}_{A}\left(\hat{p}_{1}, \ldots, \hat{p}_{N_{e}}, t\right)\right| \Psi_{g}\left(\vec{r}_{1}, \ldots, \vec{r}_{N_{e}}, t\right)\right\rangle,
\end{aligned}
$$

with

$$
\hat{V}_{A}\left(\hat{p}_{1}, \ldots, \hat{p}_{N_{e}}, t\right)=\sum_{l=1}^{N_{e}}\left(-\frac{e \hat{p}_{l} \cdot \vec{A}(t)}{m_{e}}+\frac{e^{2} A(t)^{2}}{2 m_{e}}\right),
$$

and $\hat{p}_{i}=-i \vec{\nabla}_{\vec{r}_{i}}\left(i=1, \ldots, N_{e}\right)$.
Therefore, by using similar treatments of Keldysh ${ }^{24,32}$ and KFR (Ref. 33) and under the assumption that the ionization only takes place from the HOMO, the photoionization rate constant can be formulated as

$$
\begin{aligned}
k(\vec{F})= & 2 \pi S^{2} \sum_{j, j^{\prime}=1}^{N_{e}} c_{j} c_{j^{\prime}}^{*} \int \frac{d^{2} p}{(2 \pi)^{3}} \hat{\chi}_{j}(\vec{p}) \hat{\chi}_{j}^{*}(\vec{p})\left(\frac{p^{2}}{2 m_{e}}+I_{0}\right)^{2} \mid \\
& \times\left. J_{N}\left(\frac{e \vec{F} \cdot \vec{p}}{m_{e} \omega^{2}}, \frac{U}{2 \omega}\right)\right|^{2} \cos \left(\vec{p} \cdot\left(\vec{R}_{j}-\vec{R}_{j^{\prime}}\right)\right) \\
& \times \sum_{N=-\infty}^{\infty} \delta\left(I_{0}+U+\frac{p^{2}}{2 m_{e}}-N \omega\right) \\
= & \sum_{N} 2 \pi S^{2} \sum_{j, j^{\prime}=1}^{N_{e}} c_{j} c_{j^{\prime}}^{*} \frac{d^{3} p}{(2 \pi)^{3}} \hat{\chi}_{j} \\
& \times(\vec{p}) \hat{\chi}_{j}^{*}(\vec{p})\left(\frac{p^{2}}{2 m_{e}}+I_{0}\right)^{2}\left|J_{N}\left(\frac{e \vec{F} \cdot \vec{p}}{m_{e} \omega^{2}}, \frac{U}{2 \omega}\right)\right|^{2} \\
& \times \cos \left(\vec{p} \cdot\left(\vec{R}_{j}-\vec{R}_{j^{\prime}}\right)\right) \delta\left(I_{0}+U+\frac{p^{2}}{2 m_{e}}-N \omega\right)^{2} \\
& \times \sum_{N>\left(l_{e}+U\right) / \omega} k_{N},
\end{aligned}
$$

where $J_{N}$ is the generalized Bessel function, ${ }^{31} c_{j}$ denotes the coefficients of the linear combination of atomic orbitalsmolecular orbital, $I_{0}$ is the ionization potential of molecule, $U=(e F)^{2} /\left(4 m_{e} \omega^{2}\right)$ is the ponderomotive potential associated with the optical field, $S=\sqrt{2}$ for the closed shell parent molecule or molecular cation, and $S=1$ for the open shell. In addition, for multi-ionization of molecules, we consider the following sequential ionization process:

$$
M \stackrel{k_{1}}{\longrightarrow} M^{+} \stackrel{k_{2}}{\longrightarrow} M^{2+} \ldots \stackrel{k_{3}}{\longrightarrow} M^{n+},
$$

where $k_{i}$ is the photoionization rate constant of $M^{i+}$ cation. The rate equation can be solved if the photoionization rate constant is assumed to be independent of the laser time $t$ during pulse duration. ${ }^{26,34}$ This assumption has been checked 


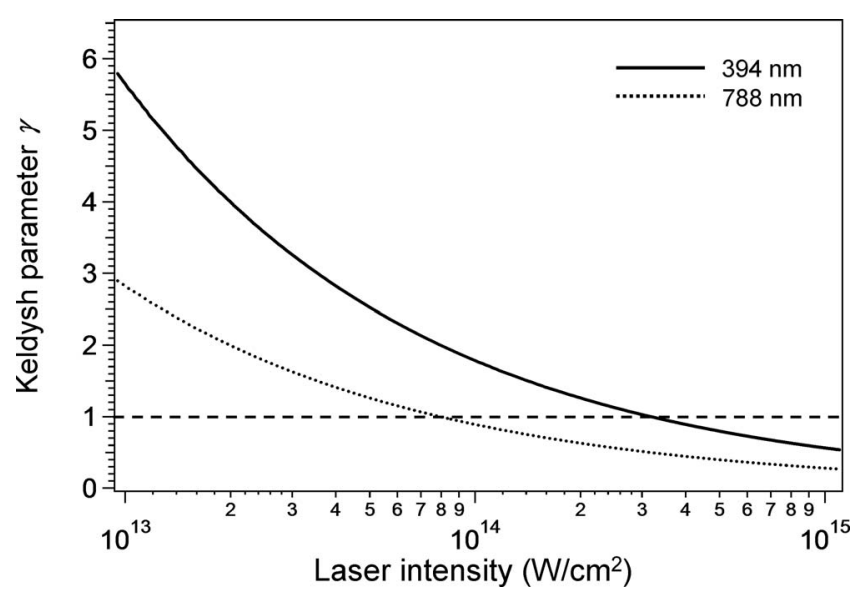

FIG. 5. Keldysh parameter as a function of laser intensity ranging from 1 $\times 10^{13} \mathrm{~W} / \mathrm{cm}^{2}$ to $1 \times 10^{15} \mathrm{~W} / \mathrm{cm}^{2}$ for 394 and $788 \mathrm{~nm}$.

previously $^{26,34}$ by taking into account the laser pulse of a Gaussian shape

$$
\vec{F}(t) \cos (\omega t)=\vec{F}_{r} \exp \left(-(4 \ln 2) t^{2} /\left(\Delta t_{F}\right)^{2}\right) \cos (\omega t)
$$

for the generalized Keldysh theory where $\vec{F}_{0}$ is the peak amplitude, and $\Delta t_{F}$ is the full width at half maximum. However, it is also important to consider the spatial distribution of the laser pulse, ${ }^{35}$ and similar to the previous work, ${ }^{26}$ we assume that the laser has a Gaussian shape of the spatial distribution with the width $\Delta R$, i.e., $I(R)=I_{0} \exp \left(-8 R^{2} / \Delta R^{2}\right)$. Then the ionization yield is dependent on time and $R$, i.e., $M^{i+}(t, R)$, and we define the spatial averaged ionization yield as

$$
\overline{M^{i+}(t)}=4 \pi \int_{0}^{\infty} d R R^{2} M^{i+}(t, R) .
$$

\section{B. Calculation results}

The Keldysh or adiabatic parameter $\gamma=\omega \sqrt{2 m I_{0}} /(e F)$, which denotes the ratio of the tunneling time to the optical period, is frequently used to qualitatively identify the mechanism of ionization. In this expression, $I_{0}$ denotes the ionization energy. If $\gamma \gg 1$ the multiphoton ionization (MPI) process dominates and if $\gamma \ll 1$ field ionization occurs.

The calculated values of Keldysh parameter versus laser intensity are shown in Fig. 5 for both wavelengths. At $394 \mathrm{~nm}$, when laser intensity is lower than $10^{14} \mathrm{~W} / \mathrm{cm}^{2}, \gamma$ $>1$ means MPI is dominant. As laser intensity increased, the value of $\gamma$ tends to 1 and the effect of tunneling ionization cannot be neglected. On the contrary, the MPI is predominant below $4 \times 10^{13} \mathrm{~W} / \mathrm{cm}^{2}$ for $788 \mathrm{~nm}$. Thus, it is reasonable to consider absorption photon numbers, namely, MPI mechanism, when laser intensity is below $10^{14} \mathrm{~W} / \mathrm{cm}^{2}$ for $394 \mathrm{~nm}$ and $4 \times 10^{13} \mathrm{~W} / \mathrm{cm}^{2}$ for $788 \mathrm{~nm}$, respectively.

For simplicity, we calculate the ionization rate constant with the hydrogenlike atom model. The HOMO of cyclopentanone mainly consists of the $2 p$ atomic orbitals (AOs). Therefore, we replace the photoionization rate constants of $M^{n+}$ molecular cations by the one of the $2 p z$ AO with the same ionization potential, such as $9.28 \mathrm{eV}$ for the $M^{+}$and $26.61 \mathrm{eV}$ for the $M^{2+}$. In Fig. 6, the photoionization rate (a) First ionization rate constants

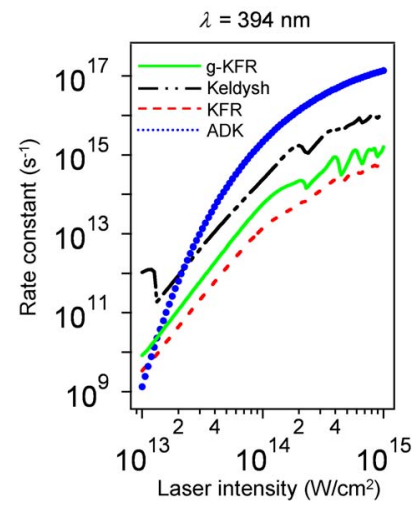

(b) First ionization rate constants

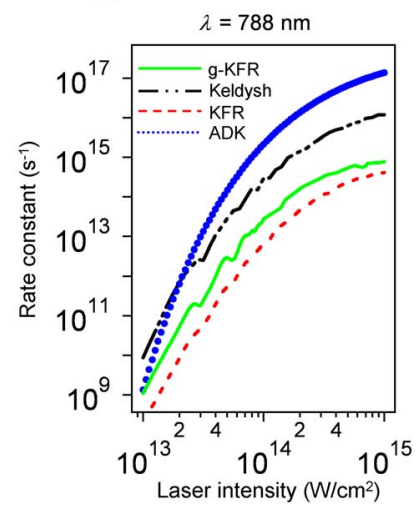

FIG. 6. (Color online) Calculation results for first ionization rate constants of cyclopentanone by using various theories, where g-KFR represents the generalized KFR theory. (a) $\lambda=394 \mathrm{~nm}$; (b) $\lambda=788 \mathrm{~nm}$.

constants of a molecule using the model of hydrogenlike atom with $2 p z$ orbital and the ionization potential of $I_{1}$ $=9.28 \mathrm{eV}$ are plotted as a function of the laser intensity for both wavelengths $\lambda=394 \mathrm{~nm}$ (a) and $788 \mathrm{~nm}$ (b). Firstly, it should be noted that for both wavelengths, the ADK theory overestimates the rate constants for high laser intensity, especially above $10^{14} \mathrm{~W} / \mathrm{cm}^{2}$, where the values of the rate constants go beyond $10^{17} \mathrm{~s}^{-1}$. Secondly, the results obtained from the Keldysh theory also tend to overestimate the rate constants for the high intensity region, reaching $k=10^{16} \mathrm{~s}^{-1}$ at $I=10^{15} \mathrm{~W} / \mathrm{cm}^{2}$. Furthermore, in the whole intensity region $\left(10^{13}<I<10^{15} \mathrm{~W} / \mathrm{cm}^{2}\right)$, the rate constants from the Keldysh theory and the KFR theory differ by a factor of $10^{1}-10^{3}$. This difference comes from the pole approximation where a contribution from a circle contour integral is neglected for the time integral in the Keldysh theory, while the time integral in KFR theory is exactly performed. Moreover, we also illustrate the second ionization rate constants of cyclopentanone ion using the model of hydrogenlike atom with $2 p z$ orbital and the ionization potential $I_{2}=26.61 \mathrm{eV}$ in Fig. 7: $\lambda=394 \mathrm{~nm}$ (a) and $788 \mathrm{~nm}$ (b). The similar trends may point out that the results from the Keldysh theory are larger than those from the ADK and the KFR theory.

As mentioned above, the HOMO of a ketone molecule is a nonbonding orbital of the $\mathrm{C}-\mathrm{O}$ group, which has the (a) Second ionization rate constants

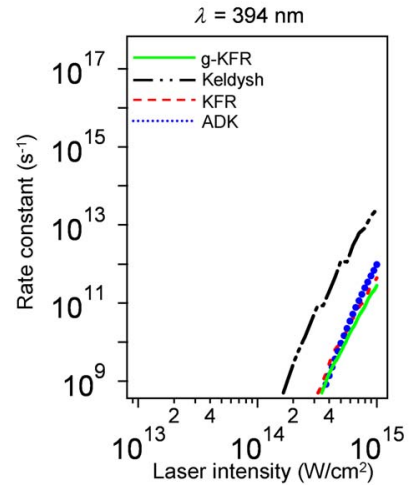

(b) Second ionization rate constants

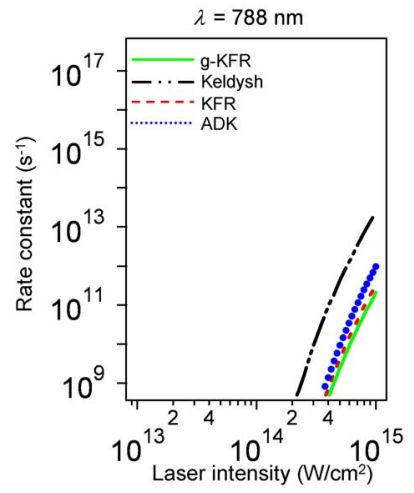

FIG. 7. (Color online) Calculation results for second ionization rate constants of cyclopentanone by using various theories, where g-KFR represents the generalized KFR theory. (a) $\lambda=394 \mathrm{~nm}$; (b) $\lambda=788 \mathrm{~nm}$. 

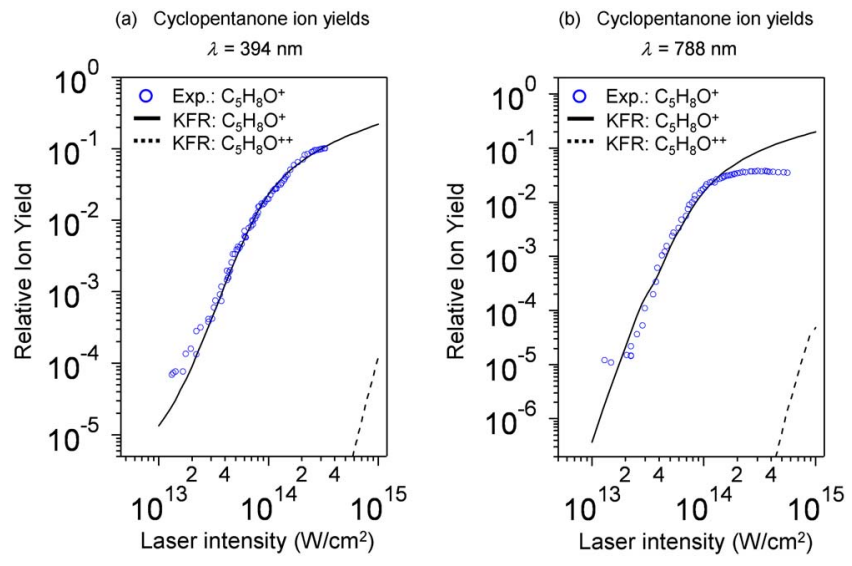

FIG. 8. (Color online) Comparison of relative ion yields between experimental and theoretical results. (a) $\lambda=394 \mathrm{~nm}$; (b) $\lambda=788 \mathrm{~nm}$. The dot represents experimental result of $\mathrm{C}_{5} \mathrm{H}_{8} \mathrm{O}^{+}$while the line corresponds to theoretical one. The dashed denotes the theoretical prediction of the ion yield for $\mathrm{C}_{5} \mathrm{H}_{8} \mathrm{O}^{++}$.

$p$-orbital character. For the purpose of comparing the performance of the ADK, KFR, and Keldysh calculations, a $2 p$ orbital has been used and the results are shown in Fig. 6 . However, in the generalized KFR theory case, a realistic HOMO has been used in which the $2 p$ orbital is mixed with a $3 p$ orbital. For $394 \mathrm{~nm}$, the results are shown in Figs. 6(a) and $7(\mathrm{a})$. It is notable that the rate constants of the second ionization are much smaller than those of the first ionization, differ by a factor $10^{4}$ at $I=10^{15} \mathrm{~W} / \mathrm{cm}^{2}$ and even larger for $I<10^{15} \mathrm{~W} / \mathrm{cm}^{2}$. In Fig. 8(a), the ion yields of cyclopentanone molecule with a single and double charge are illustrated at $394 \mathrm{~nm}$. Since the first and second ionization rate constants are quite different, the ion yield of singly charged cyclopentanone is quite larger than that of doubly charged one by a factor more than $10^{3}$. Similarly, in Fig. 8(b), we plot the ion yields of cyclopentanone molecule for the case of $788 \mathrm{~nm}$ as a function of laser intensity.

\section{DISCUSSION}

\section{A. Ionization rate constants}

First, we compare our experimental results (Fig. 1) with the conventional mass spectrum of cyclopentanone provided by NIST (Ref. 36) (Fig. 9). One can see that the peak positions of the two mass spectra are identical but the relative peak intensities differ. This is due to the fact that the energy

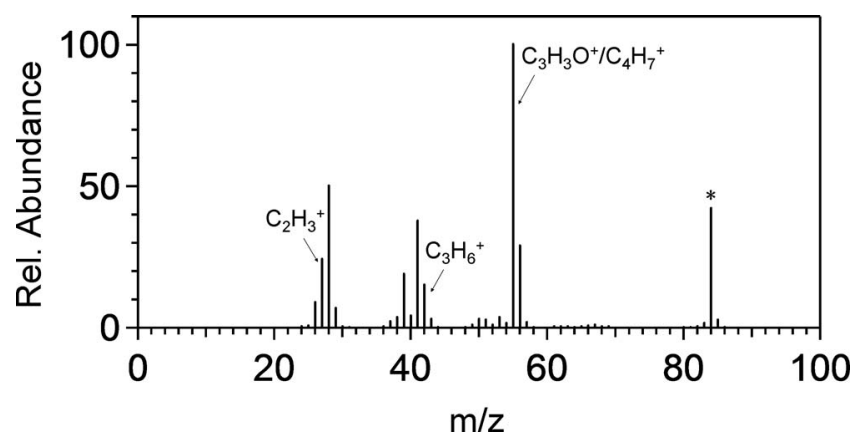

FIG. 9. Conventional mass spectrum for cyclopentanone provided by the NIST Chemistry WebBook (Ref. 36). The asterisk denotes the parent ion. deposited in the parent ion depends on the experimental method, and variations in the available internal energy result in differences in the rate constants for decomposition of the ion. In this paper, these rate constants are obtained by employing RRKM theory using ab initio potential surfaces.

We consider that ionization is followed by dissociation in our experiments because for neutral dissociation of a molecule to take place, the molecule has to absorb energy from the laser first and then either predissociate or decompose after internal conversion. The decomposition products would ionize afterwards, and all these steps have to take place within the laser pulse duration of $\sim 100 \mathrm{fs}$, making this scenario rather unlikely. Discussions of experimental data related to this issue can be found in Refs. 9, 34, and 37.

Considering the larger difference between the ion yields for singly and doubly charged cyclopentanone, a factor more than $10^{3}$, from the calculation results shown in Fig. 8, it should be hard to see the doubly charged molecular parent ion within the laser intensity used in the present experiment. This is confirmed by the experimental observations since there is no evidence for the doubly charged parent ions in all the measured mass spectra. For example, from Figs. 1(a) -1 (c), for $394 \mathrm{~nm}$ laser with the intensity below 2 $\times 10^{14} \mathrm{~W} / \mathrm{cm}^{2}$, only $\mathrm{C}_{5} \mathrm{H}_{8} \mathrm{O}^{+}$ion together with the fragment ions resulted from its dissociation are produced. Actually, the ion peak at $m / z=42$ can be attributed to $\mathrm{C}_{3} \mathrm{H}_{6}^{+}$from the dissociation other than the doubly charged parent ion. When increasing the laser intensity up to $3 \times 10^{14} \mathrm{~W} / \mathrm{cm}^{2}, \mathrm{C}^{2+}$ ions begin to be detectable, most probably from further ionization of the fragment $\mathrm{C}^{+}$in this $90 \mathrm{fs}$ laser field. The similar trend can also be found in $788 \mathrm{~nm}$ case and, based on the calculations mentioned above, the $\mathrm{C}_{5} \mathrm{H}_{8} \mathrm{O}^{++}$ion does not appear.

The wavelength dependence of the ionization can be explained simply by the hydrogenlike theoretical model. From Fig. 6, we can also find a similar dependence of the wavelength based on the Keldysh theory and KFR theory. If the wavelength becomes shorter, both results become more flat keeping the asymptotic behavior for higher intensity around $I=10^{15} \mathrm{~W} / \mathrm{cm}^{2}$ where the rate constants from the Keldysh (KFR) theory seem to converge to a value of order $10^{16}$ $\left(10^{14}\right) \mathrm{s}^{-1}$. Furthermore, by comparing the results for 394 and $788 \mathrm{~nm}$ with the same theoretical model in Fig. 6, especially for KFR theory, we observe that the first ionization rate constants for $394 \mathrm{~nm}$ are higher than those for $788 \mathrm{~nm}$ if laser intensity is below $10^{14} \mathrm{~W} / \mathrm{cm}^{2}$. According to the Keldysh parameter illustrated in Fig. 5, within this laser range, MPI mechanism may play an important role in the ionization process for both wavelengths. Thus, the ionization probability of cyclopentanone under the $394 \mathrm{~nm}$ irradiation is larger than that under the $788 \mathrm{~nm}$ irradiation. When laser intensity is increased to nearby $10^{14} \mathrm{~W} / \mathrm{cm}^{2}$, the effect of field ionization cannot be neglected, particularly for the $788 \mathrm{~nm}$ irradiation; the laser field will then lead to nearly the same ionization probabilities for both wavelengths. As laser intensity continues to increase up to $10^{15} \mathrm{~W} / \mathrm{cm}^{2}$ or even higher, the ionization rate constants become independent of the wavelength.

From comparison of the theoretical and experimental results as shown in Figs. 8(a) and 8(b), it is clear that the 
theoretical calculated ion yields of $\mathrm{C}_{5} \mathrm{H}_{8} \mathrm{O}^{+}$fit well with the experimental observations for the $394 \mathrm{~nm}$ case. From the calculated curve, a value of theoretical slope ranging from 2.9 to 3.4 for $I=(5-7) \times 10^{13} \mathrm{~W} / \mathrm{cm}^{2}$ is very close to the minimum number of photons required for MPI of the molecule experimentally. Nevertheless, there exists an obvious difference at $788 \mathrm{~nm}$ for the high intensity region (larger than $10^{14} \mathrm{~W} / \mathrm{cm}^{2}$ ). In Fig. 8(b), the value of theoretical slope ranges from 5.5 to 6.3 for $I=(1-3) \times 10^{13} \mathrm{~W} / \mathrm{cm}^{2}$, which is close to the minimum number of photons required for MPI of the molecule experimentally. However, when laser intensity is up to $10^{14} \mathrm{~W} / \mathrm{cm}^{2}$, the value of theoretical slope is smaller than 5 , which is quite different from the experimental value of 6.2. From Fig. 6, we can see that the ADK contribution to molecular ionization is not negligible even at $I$ $\sim 10^{13} \mathrm{~W} / \mathrm{cm}^{2}$; this indicates that the contribution from the tunneling ionization is not negligible in our laser intensity range. However, we feel that the resonance excitation processes of molecules do play a significant role in our observations since the slopes equal roughly to the numbers of photons ( $N=3$ or 6 for 394 or $788 \mathrm{~nm}$, respectively) required for ionizing the ground state molecules. With increasing laser intensity at $788 \mathrm{~nm}$, the calculated slope shifted from 6 to 5 ; this may be due to the contribution of the saturation effect involved in the ionization. In addition, the FAD (Ref. 38) would play a non-negligible role in the fragmentation as well, which also affects the performance of the laser dependence. Namely, the fragmentation is higher now than that in the $394 \mathrm{~nm}$ case in the high intensity region. On the other hand, owing to the difference of the available internal energy for various wavelengths used here, compared with the shorter wavelength condition, the longer one may stimulate more dissociation channels, especially for the higher laser intensity region. However, in fact, we do not consider the influence of dissociation when using the generalized KFR theory for calculating the photoionization rate constants. Therefore, this calculation may lead to an obvious difference between the theoretical and experimental results in this high intensity region. It is clear that further investigation is required both experimentally and theoretically.

\section{B. $A b$ initio/RRKM calculations of the dissociation mechanism}

The dissociation of molecular ions induced by an intense femtosecond laser can proceed in two ways. Within the laserpulse duration and spatial distribution, the potential surfaces of molecular ions can be modified by the laser electric field, and if the laser intensity is strong enough, it can induce the ion dissociation during the laser duration. This type of ion dissociation is usually referred such as FAD (Ref. 38) and occurs in the femtosecond range. The second type of ion dissociation takes place outside the temporal and spatial influence of the femtosecond laser pulse. In this case, the ions are hot and unstable and for reasonably large-sized ions, this type of ion dissociation can be treated by a statistical theory, for example, RRKM theory or quasiequilibrium theory. In this case, the rate constant of ion dissociation can be expressed as

$$
k(E)=\frac{1}{h} \cdot \frac{W^{*}\left(E-E_{0}^{*}\right)}{\rho(E)},
$$

where $W^{\ddagger}\left(E-E_{0}^{\neq}\right)$and $\rho(E)$ represent the total number of states of the activated complex with activation energy $E_{0}^{\neq}$ and the density of states of the reactant with energy $E$, respectively.

To study the dissociation mechanism of cyclopentanone ions, we here performed $a b$ initio quantum chemical calculations of potential energy surfaces (PESs) for $\mathrm{C}_{5} \mathrm{H}_{8} \mathrm{O}^{+}$and $\mathrm{C}_{5} \mathrm{H}_{8} \mathrm{O}^{++}$. The B3LYP/6-31G* method ${ }^{39}$ has been used to carry out geometry optimizations, and the energies of the ions have been refined by the G3(MP2,CCSD) ab initio calculations. ${ }^{40}$ The zero-point energy corrections to the total G3(MP2,CCSD) energies have been computed using B3LYP/ 6-31G* frequencies without scaling. The differences between B3LYP/6-31G** and G3(MP2,CCSD) relative energies both for local minima and barrier heights did not exceed $5-10 \mathrm{kcal} / \mathrm{mol}$, within the regular accuracy expected from the B3LYP method, and therefore geometry optimization at a higher theoretical level is not required. Also, no significant spin contamination was detected for open shell systems including $\mathrm{C}_{5} \mathrm{H}_{8} \mathrm{O}^{+}$and fragmentation products, as calculated $\left\langle\mathbf{S}^{2}\right\rangle$ values were close to 0.75 and did not exceed 0.77. Connections between transition states and local minima were checked by intrinsic reaction coordinate (IRC) calculations at the B3LYP/6-31G* level. Such calculations were carried for all significant isomerization and decomposition channels, excluding only those contributing less than $0.1 \%$ to the overall product yield. For instance, for the monocation, we computed IRC pathways for all transition states corresponding to barriers below $\sim 70 \mathrm{kcal} / \mathrm{mol}$. All ab initio calculations have been performed using the GAUSSIAN 03 (Ref. 41) and MOLPRO 2002 packages. ${ }^{42}$ B3LYP/ 6-31G* frequencies for all intermediates and transition states have been used to perform the RRKM calculation. ${ }^{34}$

\section{Dissociation of the $\mathrm{C}_{5} \mathrm{H}_{8} \mathrm{O}^{+}$monocation}

The computed adiabatic ionization potential of $\mathrm{C}_{5} \mathrm{H}_{8} \mathrm{O}$ is $9.24 \mathrm{eV}$, in close agreement with the experimental value of $9.28 \mathrm{eV}^{20}$ The multistep dissociation scheme for the $\mathrm{C}_{5} \mathrm{H}_{8} \mathrm{O}^{+}$monocation is shown in Figs. 10 and 11. The variety of possible photodissociation channels of $\mathrm{C}_{5} \mathrm{H}_{8} \mathrm{O}^{+}$is given in the following:

$$
\begin{aligned}
& \mathrm{C}_{5} \mathrm{H}_{8} \mathrm{O}^{+} \rightarrow \mathrm{C}_{4} \mathrm{H}_{8}^{+}+\mathrm{CO}, \quad m / z=56, \\
& \mathrm{C}_{5} \mathrm{H}_{8} \mathrm{O}^{+} \rightarrow \mathrm{C}_{3} \mathrm{H}_{4} \mathrm{O}^{+}+\mathrm{C}_{2} \mathrm{H}_{4}, \quad m / z=56, \\
& \mathrm{C}_{5} \mathrm{H}_{8} \mathrm{O}^{+} \rightarrow \mathrm{C}_{3} \mathrm{H}_{3} \mathrm{O}^{+}+\mathrm{C}_{2} \mathrm{H}_{5}, \quad m / z=55, \\
& \mathrm{C}_{5} \mathrm{H}_{8} \mathrm{O}^{+} \rightarrow \mathrm{C}_{3} \mathrm{H}_{6}^{+}+\mathrm{H}_{2} \mathrm{C}_{2} \mathrm{O}, \quad m / z=42, \\
& \mathrm{C}_{5} \mathrm{H}_{8} \mathrm{O}^{+} \rightarrow \mathrm{C}_{3} \mathrm{H}_{3} \mathrm{O}^{+}+\mathrm{C}_{2} \mathrm{H}_{3}, \quad m / z=57, \\
& \mathrm{C}_{5} \mathrm{H}_{8} \mathrm{O}^{+} \rightarrow \mathrm{C}_{5} \mathrm{H}_{7} \mathrm{O}^{+}+\mathrm{H}, \quad m / z=83, \\
& \mathrm{C}_{5} \mathrm{H}_{8} \mathrm{O}^{+} \rightarrow \mathrm{C}_{5} \mathrm{H}_{6} \mathrm{O}^{+}+\mathrm{H}_{2}, \quad m / z=82,
\end{aligned}
$$




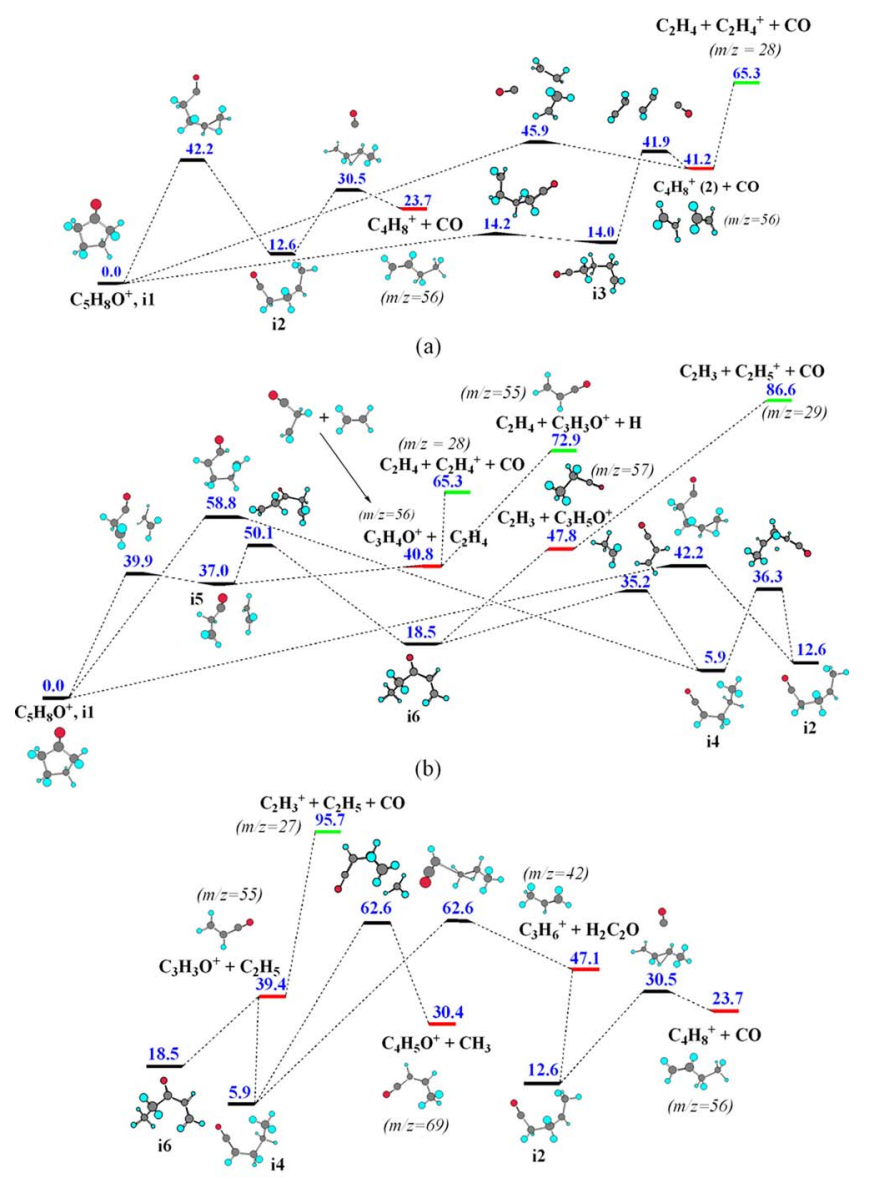

(c)

FIG. 10. (Color online) Major channels of the dissociation mechanism of $\mathrm{C}_{5} \mathrm{H}_{8} \mathrm{O}^{+}$.

$$
\mathrm{C}_{5} \mathrm{H}_{8} \mathrm{O}^{+} \rightarrow \mathrm{C}_{5} \mathrm{H}_{6}^{+}+\mathrm{H}_{2} \mathrm{O}, \quad m / z=66 .
$$

Let us first consider the $\mathrm{CO}$ elimination mechanism [Fig. $10(\mathrm{a})$ ]. Ring opening in cyclopentanone monocation $\mathrm{C}_{5} \mathrm{H}_{8} \mathrm{O}^{+}$ (i1) accompanied with 1,2-H shift gives an open-chain intermediate $\mathrm{i} 2, \mathrm{CH}_{3} \mathrm{CHCH}_{2} \mathrm{CH}_{2} \mathrm{CO}^{+}$, residing $12.6 \mathrm{kcal} / \mathrm{mol}$ above i1. This process requires a barrier of $42.2 \mathrm{kcal} / \mathrm{mol}$. Next, i2 can lose the carbonyl group producing a chain $\mathrm{C}_{4} \mathrm{H}_{8}^{+}$ structure, $\mathrm{CH}_{3} \mathrm{CH}_{2} \mathrm{CHCH}_{2}^{+}$, overcoming a transition state (TS) lying $30.5 \mathrm{kcal} / \mathrm{mol}$ above $\mathrm{i} 1$. The $\mathrm{CO}$ elimination process here goes together with $\mathrm{H}$ migration from $\mathrm{CH}_{2}$ to $\mathrm{CH}$. The overall endothermicity of this $\mathrm{i} 1 \rightarrow \mathrm{C}_{4} \mathrm{H}_{8}^{+}+\mathrm{CO}$ product channel is $23.7 \mathrm{kcal} / \mathrm{mol}$. Another $\mathrm{CO}$ elimination pathway involves ring opening to produce a $\mathrm{CH}_{2} \mathrm{CH}_{2} \mathrm{CH}_{2} \mathrm{CH}_{2} \mathrm{CO}^{+}$ intermediate i3 via a barrier of $14.2 \mathrm{kcal} / \mathrm{mol}$. The intermediate is metastable as it resides only $0.2 \mathrm{kcal} / \mathrm{mol}$ lower in energy than the ring opening transition state. i3 can further decompose to $\mathrm{C}_{4} \mathrm{H}_{8}^{+}(2)$, which is essentially a complex of neutral ethylene and its cation, $\mathrm{C}_{2} \mathrm{H}_{4} \cdots \mathrm{C}_{2} \mathrm{H}_{4}^{+}$. The $\mathrm{C}_{4} \mathrm{H}_{8}^{+}(2)$ $+\mathrm{CO}$ products reside $41.2 \mathrm{kcal} / \mathrm{mol}$ above $\mathrm{il}$ and the $\mathrm{CO}$ elimination TS is located $41.9 \mathrm{kcal} / \mathrm{mol}$ higher in energy than the initial cyclopentanone monocation. The $\mathrm{C}_{4} \mathrm{H}_{8}^{+}(2)$ $+\mathrm{CO}$ products can also be formed directly from i1 by pulling away the $\mathrm{CO}$ group via a barrier of $45.9 \mathrm{kcal} / \mathrm{mol}$. In summary, three reaction channels producing $\mathrm{C}_{4} \mathrm{H}_{8}^{+}+\mathrm{CO}$ have been found: $\mathrm{i} 1 \rightarrow \mathrm{CH}_{3} \mathrm{CHCH}_{2} \mathrm{CH}_{2} \mathrm{CO}^{+} \mathrm{i} 2$ $\rightarrow \mathrm{CH}_{3} \mathrm{CH}_{2} \mathrm{CHCH}_{2}^{+}+\mathrm{CO}, \quad \mathrm{i} 1 \rightarrow \mathrm{CH}_{2} \mathrm{CH}_{2} \mathrm{CH}_{2} \mathrm{CH}_{2} \mathrm{CO}^{+} \mathrm{i} 3$
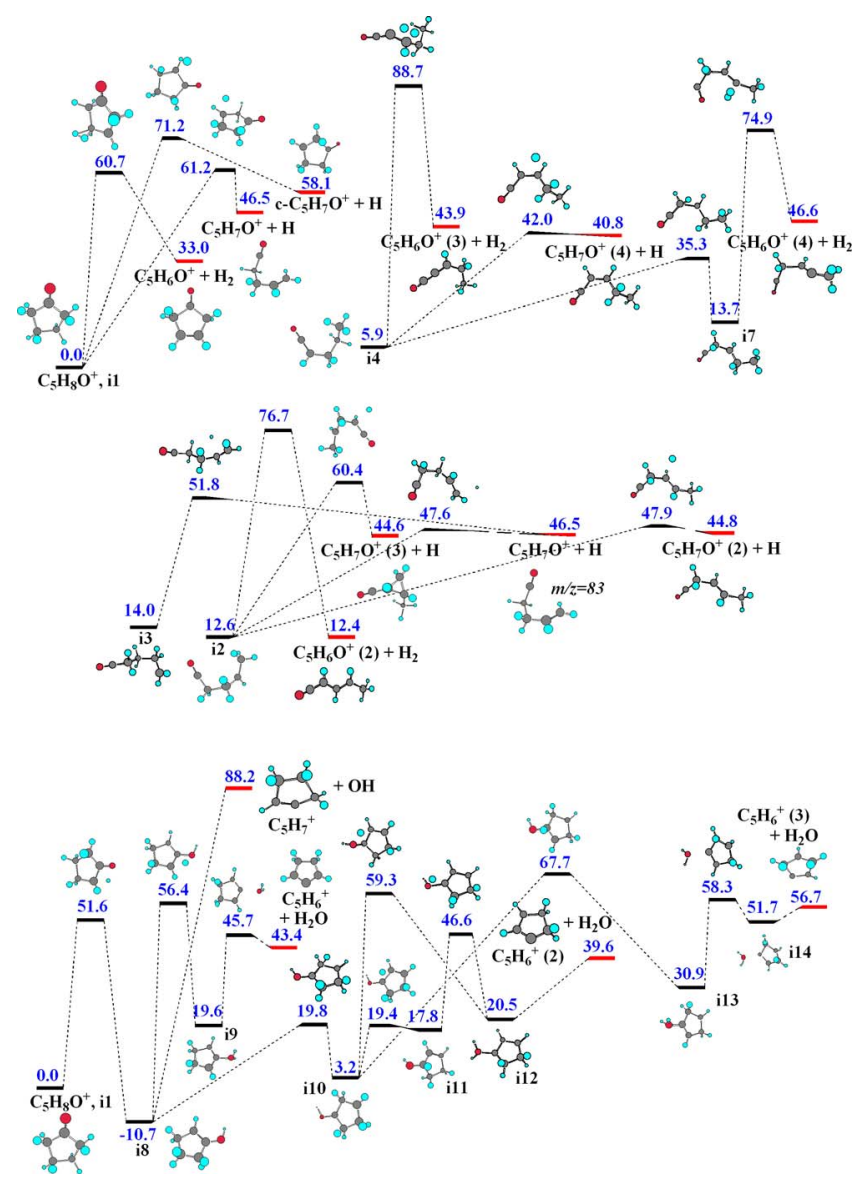

FIG. 11. (Color online) $\mathrm{H}, \mathrm{H}_{2}$, and $\mathrm{H}_{2} \mathrm{O}$ elimination channels from $\mathrm{C}_{5} \mathrm{H}_{8} \mathrm{O}^{+}$.

$\rightarrow \mathrm{C}_{4} \mathrm{H}_{8}^{+}(2)+\mathrm{CO}$, and one-step i1 $\rightarrow \mathrm{C}_{4} \mathrm{H}_{8}^{+}(2)+\mathrm{CO}$, with the highest barriers of $42.2,41.9$, and $45.9 \mathrm{kcal} / \mathrm{mol}$ relative to i1, respectively.

A number of different product channels are also feasible, but they are preceded by various rearrangements of the cation, which normally involve ring opening, $\mathrm{H}$ migrations, etc. [see Fig. 10(b)]. A 1,3-H shift between the two $\mathrm{CH}_{2}$ groups adjacent to $\mathrm{CO}$ accompanied with ring opening via the cleavage of the $\mathrm{C}(\mathrm{O})-\mathrm{CH}_{2}$ bond leads to the intermediate i4, $\mathrm{CH}_{3} \mathrm{CH}_{2} \mathrm{CH}_{2} \mathrm{CHCO}^{+}(5.9 \mathrm{kcal} / \mathrm{mol}$ above $\mathrm{i} 1)$, via a barrier of $58.8 \mathrm{kcal} / \mathrm{mol}$. This process is rather peculiar. According to IRC calculations ran from the transition state all the way down to $\mathrm{i} 1$ and i4, before the TS an $\mathrm{H}$ atom moves from a $\mathrm{CH}_{2}$ group to the $\mathrm{CO}$ carbon atom while the bond connecting this atom with the other neighboring $\mathrm{CH}_{2}$ group elongates and starts to break. After the barrier is cleared, the moving $\mathrm{H}$ atom continues its motion, leaves the carbonyl carbon, and eventually forms a $\mathrm{CH}_{3}$ group while the $\mathrm{C}(\mathrm{O})-\mathrm{CH}_{2}$ bond cleavage completes. Meanwhile, there exists a three-step lower energy pathway from i1 to i4. At the first step, ring opening occurs along the $\mathrm{CH}_{2}-\mathrm{CH}_{2}$ bond opposite to the $\mathrm{CO}$ group. This process leads to the formation of $\mathrm{CH}_{2} \mathrm{CH}_{2} \cdots \mathrm{C}(\mathrm{O}) \mathrm{CH}_{2} \mathrm{CH}_{2}^{+}$i5 over a barrier of $39.9 \mathrm{kcal} / \mathrm{mol}$. The intermediate i5 lying $37.0 \mathrm{kcal} / \mathrm{mol}$ higher in energy than i1 can undergo 1,4-H migration to a terminal $\mathrm{CH}_{2}$ group to produce the intermediate $\mathrm{i} 6, \mathrm{CH}_{3} \mathrm{CH}_{2} \mathrm{COCHCH}_{2}^{+}$, $18.5 \mathrm{kcal} / \mathrm{mol}$ above i1, via a TS positioned $50.1 \mathrm{kcal} / \mathrm{mol}$ higher in energy than i1. Next, i6 rearranges to i4 by a 1,3- 
shift of the $\mathrm{C}_{2} \mathrm{H}_{5}$ moeity overcoming a barrier of 17.0 (35.2) $\mathrm{kcal} / \mathrm{mol}$ relative to i6 (i1). One can see that the highest barrier on the multistep $\mathrm{i} 1 \rightarrow \mathrm{i} 5 \rightarrow \mathrm{i} 6 \rightarrow \mathrm{i} 4$ pathway is $50.1 \mathrm{kcal} / \mathrm{mol}$ with respect to $\mathrm{i} 1$, significantly lower than $58.8 \mathrm{kcal} / \mathrm{mol}$ for the direct $\mathrm{i} 1 \rightarrow \mathrm{i} 4$ process. Finally, i4 can further isomerize to i2 by $1,3-\mathrm{H}$ migration between the $\mathrm{CH}_{2}$ and $\mathrm{CH}$ groups via a TS lying $36.3 \mathrm{kcal} / \mathrm{mol}$ above $\mathrm{i} 1$.

In addition to $\mathrm{C}_{4} \mathrm{H}_{8}^{+}+\mathrm{CO}$, the intermediate $\mathrm{i} 2$ can give rise to the $\mathrm{C}_{3} \mathrm{H}_{6}^{+}\left(\mathrm{CH}_{3} \mathrm{CHCH}_{2}^{+}\right)+\mathrm{H}_{2} \mathrm{C}=\mathrm{C}=\mathrm{O}$ products, which lie $47.1 \mathrm{kcal} / \mathrm{mol}$ higher in energy than i1 [Fig. 10(c)]. In this case, the cleavage of the $\mathrm{CH}_{2}-\mathrm{CH}_{2}$ bond nearest to the carbonyl group occurs without an exit barrier. Also, in principle, $\mathrm{H}$ migration between two $\mathrm{CH}_{2}$ groups followed by the cleavage of the $\mathrm{C}-\mathrm{C}$ bond connecting them could bring forward $\mathrm{C}_{3} \mathrm{H}_{7}^{+}$(2-propyl cation) $+\mathrm{HCCO}$, but since these products lie $70.9 \mathrm{kcal} / \mathrm{mol}$ higher in energy than i1, we do not consider the details of this channel further. i4 can dissociate to three different product pairs, $\mathrm{C}_{3} \mathrm{H}_{3} \mathrm{O}^{+}+\mathrm{C}_{2} \mathrm{H}_{5}$, $39.4 \mathrm{kcal} / \mathrm{mol}$ above $\mathrm{i} 1$, without an exit barrier; $\mathrm{C}_{4} \mathrm{H}_{5} \mathrm{O}^{+}$ $+\mathrm{CH}_{3}, 30.4 \mathrm{kcal} / \mathrm{mol}$ higher in energy than i1, via a barrier of $62.6 \mathrm{kcal} / \mathrm{mol}$ relative to $\mathrm{i} 1$; and $\mathrm{C}_{3} \mathrm{H}_{6}^{+}+\mathrm{H}_{2} \mathrm{C}=\mathrm{C}=\mathrm{O}$, $47.1 \mathrm{kcal} / \mathrm{mol}$ above $\mathrm{i} 1$, via a TS involving two simultaneous 1,2-H shifts accompanying the $\mathrm{C}-\mathrm{C}$ bond cleavage and residing $62.6 \mathrm{kcal} / \mathrm{mol}$ above the initial $\mathrm{C}_{5} \mathrm{H}_{8} \mathrm{O}^{+}$monocation. 15 can easily lose the $\mathrm{C}_{2} \mathrm{H}_{4}$ fragment with the formation of the $\mathrm{C}_{3} \mathrm{H}_{4} \mathrm{O}^{+}\left(\mathrm{CH}_{2} \mathrm{CH}_{2} \mathrm{CO}^{+}\right)$cation, where the $\mathrm{C}_{3} \mathrm{H}_{4} \mathrm{O}^{+}+\mathrm{C}_{2} \mathrm{H}_{4}$ products lie $40.8 \mathrm{kcal} / \mathrm{mol}$ above the initial $\mathrm{C}_{5} \mathrm{H}_{8} \mathrm{O}^{+}$monocation. Finally, structure i6 can eliminate either $\mathrm{C}_{2} \mathrm{H}_{5}$ or $\mathrm{C}_{2} \mathrm{H}_{3}$ groups producing $\mathrm{C}_{3} \mathrm{H}_{3} \mathrm{O}^{+}$and $\mathrm{C}_{3} \mathrm{H}_{5} \mathrm{O}^{+}$ with overall endothermicities of 39.4 and $47.8 \mathrm{kcal} / \mathrm{mol} \mathrm{rela}-$ tive to i1, respectively, and without exit barriers. In terms of the activation energy required (the highest barrier on the reaction pathway or reaction endothermicity in case of dissociation steps occurring without an exit barrier), the product channels described here can be ranked as follows: $\mathrm{i} 1 \rightarrow \mathrm{i} 5$ $\rightarrow \mathrm{C}_{3} \mathrm{H}_{4} \mathrm{O}^{+}+\mathrm{C}_{2} \mathrm{H}_{4} \quad(40.8 \mathrm{kcal} / \mathrm{mol}), \quad \mathrm{i} 1 \rightarrow \mathrm{i} 2 \rightarrow \mathrm{C}_{3} \mathrm{H}_{6}^{+}$ $+\mathrm{H}_{2} \mathrm{C}=\mathrm{C}=\mathrm{O} \quad(47.1 \mathrm{kcal} / \mathrm{mol}), \quad \mathrm{i} 1 \rightarrow \mathrm{i} 5 \rightarrow \mathrm{i} 6 \rightarrow \mathrm{i} 4$ $\rightarrow \mathrm{C}_{3} \mathrm{H}_{3} \mathrm{O}^{+}+\mathrm{C}_{2} \mathrm{H}_{5}, \cdots \mathrm{i} 6 \rightarrow \mathrm{C}_{3} \mathrm{H}_{3} \mathrm{O}^{+}+\mathrm{C}_{2} \mathrm{H}_{5}, \quad$ and $\cdots \mathrm{i} 6$ $\rightarrow \mathrm{C}_{3} \mathrm{H}_{5} \mathrm{O}^{+}+\mathrm{C}_{2} \mathrm{H}_{3}$ (all $50.1 \mathrm{kcal} / \mathrm{mol}$ ), followed by much less favorable $\cdots \mathrm{i} 4 \rightarrow \mathrm{C}_{3} \mathrm{H}_{6} \mathrm{O}^{+}+\mathrm{H}_{2} \mathrm{C}=\mathrm{C}=\mathrm{O}$ and $\cdots \mathrm{i} 4$ $\rightarrow \mathrm{C}_{4} \mathrm{H}_{5} \mathrm{O}^{+}+\mathrm{CH}_{3}$ (both $62.6 \mathrm{kcal} / \mathrm{mol}$ ).

Now we consider $\mathrm{H}$ and $\mathrm{H}_{2}$ elimination pathways (Fig. 11). Starting from the cyclic structure $i 1$, the $\mathrm{H}$ loss from the meta carbon (relative to the $\mathrm{CO}$ group) is accompanied with ring opening to produce an open chain $\mathrm{C}_{5} \mathrm{H}_{7} \mathrm{O}^{+}$isomer $\mathrm{CH}_{2} \mathrm{CHCH}_{2} \mathrm{CH}_{2} \mathrm{CO}^{+}$residing $46.5 \mathrm{kcal} / \mathrm{mol}$ above the reactant. However, the barrier for this process is rather high, $61.2 \mathrm{kcal} / \mathrm{mol}$. A cyclic $c-\mathrm{C}_{5} \mathrm{H}_{7} \mathrm{O}^{+}$product, residing $58.1 \mathrm{kcal} / \mathrm{mol}$ higher in energy than $\mathrm{i} 1$, can be formed by $\mathrm{H}$ elimination from the meta position but the barrier in this case is higher, $71.2 \mathrm{kcal} / \mathrm{mol}$. The $\mathrm{CH}_{2} \mathrm{CHCH}_{2} \mathrm{CH}_{2} \mathrm{CO}^{+}$product can be also formed by $\mathrm{H}$ elimination from the terminal $\mathrm{CH}_{3}$ group in i2 and from the next-to-terminal $\mathrm{CH}_{2}$ group in i3, with lower barriers of 47.6 and $51.8 \mathrm{kcal} / \mathrm{mol}$ relative to i1, respectively. The intermediate $\mathrm{i} 2$ can also eliminate a hydrogen atom from two different $\mathrm{CH}_{2}$ group producing $\mathrm{C}_{5} \mathrm{H}_{7} \mathrm{O}^{+}$ (2), $\mathrm{CH}_{3} \mathrm{CHCHCH}_{2} \mathrm{CO}^{+}$, and $\mathrm{C}_{5} \mathrm{H}_{7} \mathrm{O}^{+}$(3) featuring a threemember carbon ring. These processes are calculated to be endothermic by 44.8 and $44.6 \mathrm{kcal} / \mathrm{mol}$ with respect to i1 and the corresponding TSs lie 47.9 and $60.4 \mathrm{kcal} / \mathrm{mol}$, respectively, above i1. Finally, $\mathrm{H}$ elimination from the central $\mathrm{CH}_{2}$ group in $\mathrm{i} 4$ produces $\mathrm{C}_{5} \mathrm{H}_{7} \mathrm{O}^{+}(4), \mathrm{CH}_{3} \mathrm{CH}_{2} \mathrm{CHCHCO}^{+}$, with the barrier and endothermicity of 42.0 and $40.8 \mathrm{kcal} / \mathrm{mol}$ relative to i1. In summary, the most favorable $\mathrm{H}$ loss channels (their highest activation barriers) are the following: $\mathrm{i} 1 \rightarrow \mathrm{i} 2 \rightarrow \mathrm{CH}_{2} \mathrm{CHCH}_{2} \mathrm{CH}_{2} \mathrm{CO}^{+}(47.6 \mathrm{kcal} / \mathrm{mol})$, i 1 $\rightarrow \mathrm{i} 2 \rightarrow \mathrm{CH}_{3} \mathrm{CHCHCH}_{2} \mathrm{CO}^{+}(47.9 \mathrm{kcal} / \mathrm{mol})$, and $\mathrm{i} 1 \rightarrow \mathrm{i} 5$ $\rightarrow \mathrm{i} 6 \rightarrow \mathrm{i} 4 \rightarrow \mathrm{CH}_{3} \mathrm{CH}_{2} \mathrm{CHCHCO}^{+}(50.1 \mathrm{kcal} / \mathrm{mol})$.

Molecular hydrogen elimination is less favorable than an $\mathrm{H}$ atom loss. For instance, the $\mathrm{H}_{2}$ splitting from the cyclic $\mathrm{C}_{5} \mathrm{H}_{8} \mathrm{O}^{+}$structure i1 requires a $60.7 \mathrm{kcal} / \mathrm{mol}$ barrier and produces cyclic $\mathrm{C}_{5} \mathrm{H}_{6} \mathrm{O}^{+}$with endothermicity of $33.0 \mathrm{kcal} / \mathrm{mol} . \mathrm{H}_{2}$ loss from i2 forms a more stable chain $\mathrm{C}_{5} \mathrm{H}_{6} \mathrm{O}^{+}$(2) isomer, $\mathrm{CH}_{3} \mathrm{CHCHCHCO}^{+}, 12.3 \mathrm{kcal} / \mathrm{mol}$ above $\mathrm{i} 1$, but the barrier is even higher, $76.7 \mathrm{kcal} / \mathrm{mol}$. From $\mathrm{i} 4$, molecular hydrogen can be eliminated either directly, producing $\mathrm{C}_{5} \mathrm{H}_{6} \mathrm{O}^{+}(3), \mathrm{CH}_{3} \mathrm{CH}_{2} \mathrm{CHCCO}^{+}$, via a higher barrier of $88.7 \mathrm{kcal} / \mathrm{mol}$, or following $\mathrm{H}$ migration and giving rise to $\mathrm{C}_{5} \mathrm{H}_{6} \mathrm{O}^{+}$(4), $\mathrm{CH}_{3} \mathrm{CCHCH}_{2} \mathrm{CO}^{+}$, with a barrier of $74.9 \mathrm{kcal} / \mathrm{mol}$ for the final step. Because of such high barriers, we do not expect the $\mathrm{H}_{2}$ loss to play any significant role.

The cyclopentanone cation il can also eliminate a water molecule. All $\mathrm{H}_{2} \mathrm{O}$ loss pathways start from the cyclic intermediate i8 produced from i1 by the $1,3-\mathrm{H}$ shift from an ortho $\mathrm{CH}_{2}$ group to the oxygen atom via a barrier $51.6 \mathrm{kcal} / \mathrm{mol}$. i8 is $10.7 \mathrm{kcal} / \mathrm{mol}$ more stable than il and features a hydroxyl group attached to a cyclopentenelike ring. Next, another $\mathrm{CH}_{2}$ to $\mathrm{OH} 1,3-\mathrm{H}$ shift, exhibiting a barrier of $56.4 \mathrm{kcal} / \mathrm{mol}$ relative to $\mathrm{i} 1$, produces the intermediate $\mathrm{i} 9$, in which an $\mathrm{H}_{2} \mathrm{O}$ group is attached to the ring. i9 loses molecular water via a barrier of $45.7 \mathrm{kcal} / \mathrm{mol}$ with respect to i1 and the $\mathrm{C}_{5} \mathrm{H}_{6}^{+}+\mathrm{H}_{2} \mathrm{O}$ products are $43.4 \mathrm{kcal} / \mathrm{mol}$ less stable than the initial reactant. The other $\mathrm{H}_{2} \mathrm{O}$ elimination channels feature multiple hydrogen shifts around the ring prior the formation of the $\mathrm{H}_{2} \mathrm{O}$ group and its elimination. In the most favorable pathway, i8 rearranges to i10 by the $\mathrm{CH}_{2}$ to $\mathrm{CH}$ hydrogen migration, then $\mathrm{i} 10$ isomerizes to $\mathrm{i} 11$ by the $\mathrm{CH}_{2}$ to $\mathrm{C}(\mathrm{OH}) \mathrm{H}$ shift, i11 converts to $\mathrm{i} 12$ by another $1,2-\mathrm{H}$ shift from the $\mathrm{C}(\mathrm{OH})$ carbon to the oxygen atom, and finally $\mathrm{H}_{2}$ is eliminated from $\mathrm{i} 12$ giving rise to the $\mathrm{C}_{5} \mathrm{H}_{6}^{+}(2)+\mathrm{H}_{2} \mathrm{O}$ products lying $39.6 \mathrm{kcal} / \mathrm{mol}$ above i1. The highest barrier on this pathway, $46.6 \mathrm{kcal} / \mathrm{mol}$ higher in energy than i1, is found for the $\mathrm{i} 11 \rightarrow \mathrm{i} 12 \mathrm{step}$. The remaining pathways initiate from i10 and involve at least one 1,3- $\mathrm{H}$ shift and hence exhibit higher barriers. Summarizing, the preferable $\mathrm{H}_{2} \mathrm{O}$ loss channel is the following: $\mathrm{i} 1 \rightarrow \mathrm{i} 8 \rightarrow \mathrm{i} 10 \rightarrow \mathrm{i} 11 \rightarrow \mathrm{i} 12$ $\rightarrow \mathrm{C}_{5} \mathrm{H}_{6}^{+}(2)+\mathrm{H}_{2} \mathrm{O}$, with the rate-determining barrier of $51.6 \mathrm{kcal} / \mathrm{mol}$ at the first reaction step. Note that elimination of the $\mathrm{OH}$ group to produce $\mathrm{C}_{5} \mathrm{H}_{7}^{+}$, which can occur directly from i8, is $88.2 \mathrm{kcal} / \mathrm{mol}$ endothermic with respect to i1 and thus unlikely to happen.

One can see that many different $\mathrm{C}_{5} \mathrm{H}_{8} \mathrm{O}^{+}$decomposition channels are feasible with the rate-controlling barriers lying in the range of $41-52 \mathrm{kcal} / \mathrm{mol}$. To evaluate the contribution of various dissociation products to the total yield more quantitatively, RRKM calculations of rate constants and product branching ratios are required. According to such calculations, the dissociation yields depend on the internal energy and the 

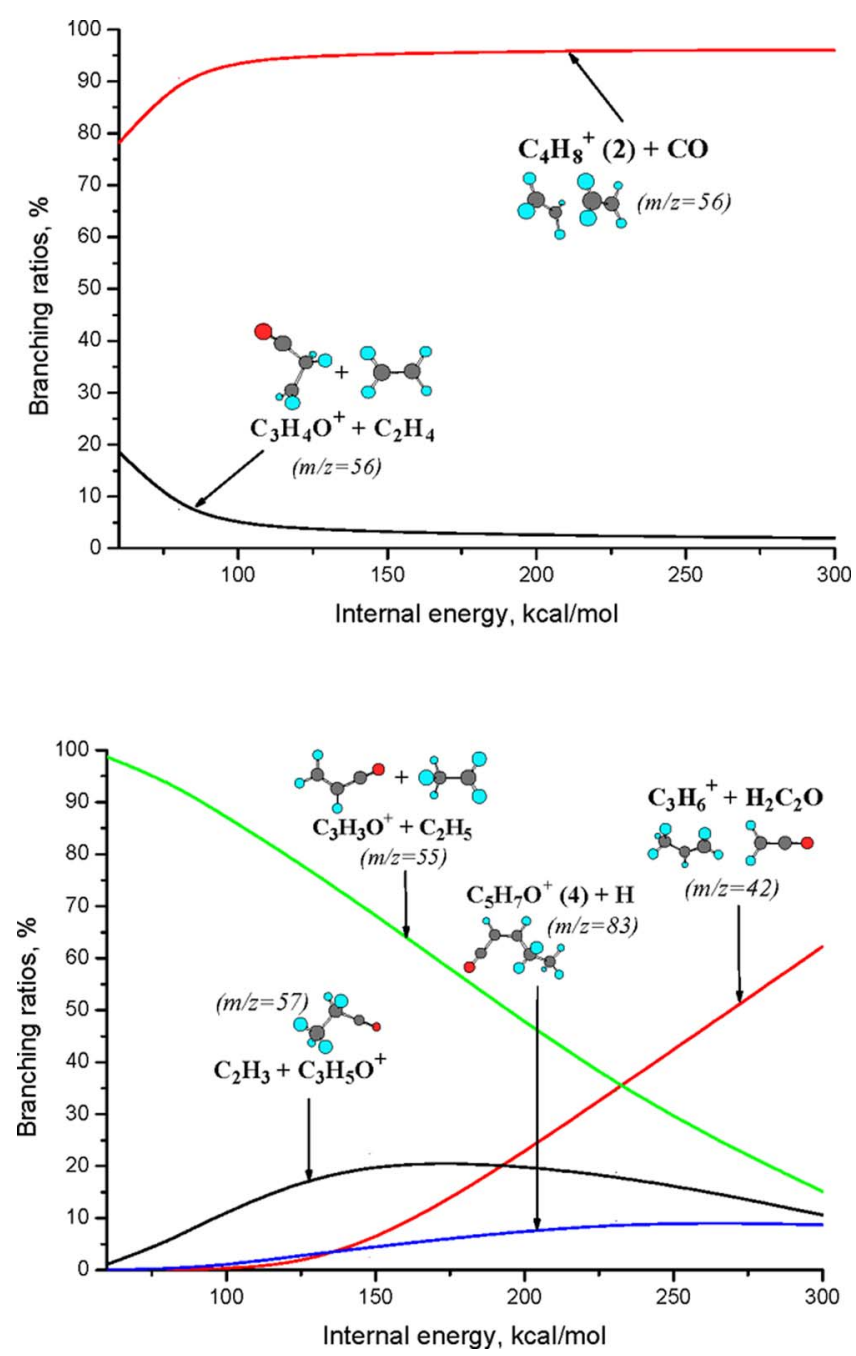

FIG. 12. (Color online) Calculated branching ratios in dissociation of $\mathrm{C}_{5} \mathrm{H}_{8} \mathrm{O}^{+}$: (a) starting from i1; (b) starting from i6.

initial intermediate from which the dissociation starts (Fig. 12). One can see that if the initial energized intermediate is the cyclic i1 structure [Fig. 12(a)], the dominant reaction products $(80 \%-95 \%)$ are $\mathrm{C}_{4} \mathrm{H}_{8}^{+}$ (the $\mathrm{C}_{2} \mathrm{H}_{4} \cdots \mathrm{C}_{2} \mathrm{H}_{4}^{+}$complex) $+\mathrm{CO}$ and the only other significant products $(20 \%-5 \%)$ are $\mathrm{C}_{3} \mathrm{H}_{4} \mathrm{O}^{+}+\mathrm{C}_{2} \mathrm{H}_{4}$. These results can account only for the $m / z=56$ peak in the spectra; the peaks at $m / z=55,28$, and 27 also observed even at the lowest laser field intensity at $\lambda=394 \mathrm{~nm}$ can be explained only if secondary dissociation is invoked (see below). Nevertheless, the higher intensity of the $m / z=55$ peak compared to that of $m / z=56$ cannot be understood from these data. The monocation formed after multiphoton ionization can, in principle, absorb more photons to populate excited states and, to understand the mechanism of subsequent dissociation, we studied the first excited PES of $\mathrm{C}_{5} \mathrm{H}_{8} \mathrm{O}^{+}$in the vicinity of the equilibrium structure of the monocation using multireference configuration interaction calculations ${ }^{43}$ with $(11,11)$ active space and Dunning's aug-cc-pVTZ basis set. ${ }^{44}$ As seen in Fig. 13, although the vertical excitation energy of $\mathrm{C}_{5} \mathrm{H}_{8} \mathrm{O}^{+}$is rather high, $74.3 \mathrm{kcal} / \mathrm{mol}$, as the ring starts to open, the energies of the ground and excited states approach each other and their surfaces are likely to cross in the energy range of

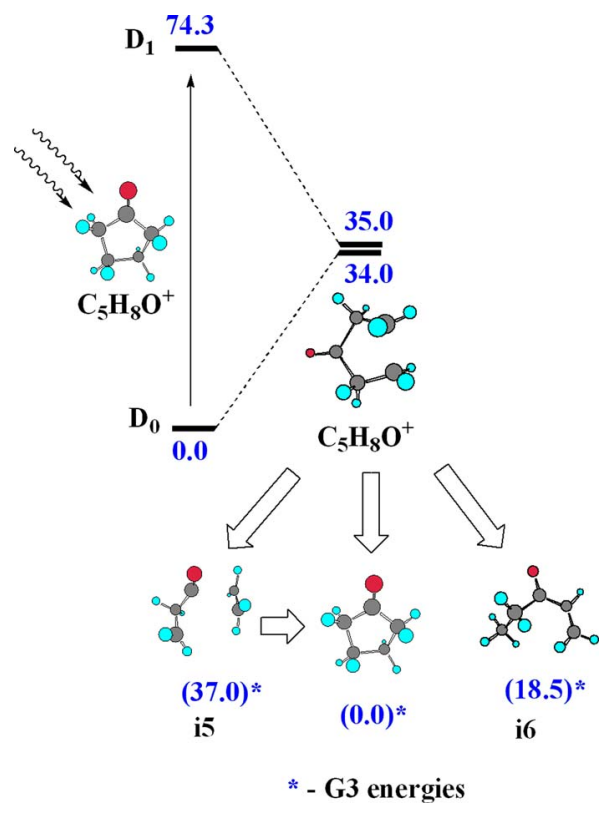

FIG. 13. (Color online) Mechanism of relaxation of $\mathrm{C}_{5} \mathrm{H}_{8} \mathrm{O}^{+}$from the first excited electronic state.

$\sim 35 \mathrm{kcal} / \mathrm{mol}$. Although we have not optimized a conical intersection geometry, we found a structure in this vicinity, for which the energy difference between the ground and first excited states is less than $1 \mathrm{kcal} / \mathrm{mol}$, strongly suggesting an existence of a crossing point. The possibility and importance of such surface crossing with formation of an open-chain diradical structure in the ground electronic state was observed by Pedersen et al. for neutral cyclopentanone. ${ }^{45}$ If such crossing does indeed occur and the internal conversion takes place at an open-chain rather than cyclic geometry, the initial energized intermediates in the ground electronic state may be not only i1, but also i5 and i6 i5 is separated from i1 by a very low barrier of $2.9 \mathrm{kcal} / \mathrm{mol}$ and so its dissociation pattern is not expected to be different from that for i1. For i6, we carried out RRKM calculations considering this intermediate as the initial energized species and the resulting product branching ratios illustrated in Fig. 12(b) are rather distinct from those obtained for cyclic $\mathrm{C}_{5} \mathrm{H}_{8} \mathrm{O}^{+}$. The dominant dissociation channel at internal energies below $150 \mathrm{kcal} / \mathrm{mol}$ is $\mathrm{C}_{3} \mathrm{H}_{3} \mathrm{O}^{+}+\mathrm{C}_{2} \mathrm{H}_{5}$. The $\mathrm{C}_{3} \mathrm{H}_{5} \mathrm{O}^{+}+\mathrm{C}_{2} \mathrm{H}_{3}$ channel starts to contribute early, and at the higher energies the $\mathrm{C}_{3} \mathrm{H}_{6}^{+}+\mathrm{H}_{2} \mathrm{C}_{2} \mathrm{O}$ and $\mathrm{C}_{5} \mathrm{H}_{7} \mathrm{O}^{+}+\mathrm{H}$ products also exhibit noticeable yields. This result can account for the high intensity of the observed $m / z=55$ peak and also for the appearance of the $m / z=42$ peak at higher laser intensities. On the other hand, the peaks with $m / z=57$ and 83 are practically not present in the mass spectra indicating that apparently $\mathrm{C}_{3} \mathrm{H}_{5} \mathrm{O}^{+}$and $\mathrm{C}_{5} \mathrm{H}_{7} \mathrm{O}^{+}$do not survive secondary dissociation.

\section{Secondary dissociation of primary monocation products}

If the primary dissociation products possess enough internal energy (or if they themselves absorb additional laser photons and become vibrationally hot after internal conversion to the ground electronic state following the photon absorption), they can undergo secondary decomposition. Here, 


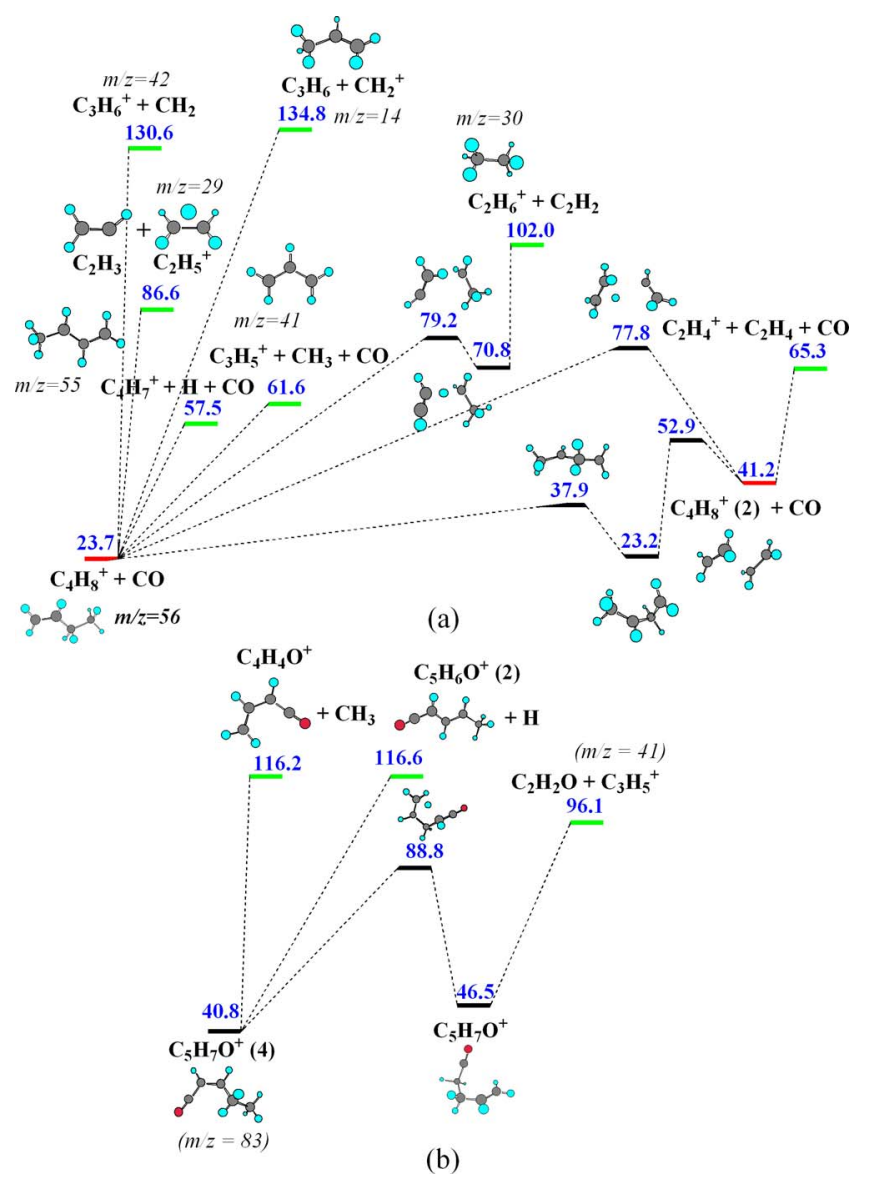

FIG. 14. (Color online) Secondary dissociation channels of $\mathrm{C}_{4} \mathrm{H}_{8}^{+}$(a) and $\mathrm{C}_{5} \mathrm{H}_{7} \mathrm{O}^{+}(\mathrm{b})$.

we address the most important primary products, such as $\mathrm{C}_{4} \mathrm{H}_{8}^{+}, \mathrm{C}_{3} \mathrm{H}_{4} \mathrm{O}^{+}, \mathrm{C}_{5} \mathrm{H}_{7} \mathrm{O}^{+}, \mathrm{C}_{3} \mathrm{H}_{5} \mathrm{O}^{+}$, and $\mathrm{C}_{3} \mathrm{H}_{3} \mathrm{O}^{+}$. Dissociation of $\mathrm{C}_{4} \mathrm{H}_{8}^{+}$is described in the following [Fig. 14(a)],

$$
\begin{aligned}
& \mathrm{C}_{4} \mathrm{H}_{8}^{+} \rightarrow \mathrm{C}_{2} \mathrm{H}_{4}^{+}+\mathrm{C}_{2} \mathrm{H}_{4}, \quad m / z=28, \\
& \mathrm{C}_{4} \mathrm{H}_{8}^{+} \rightarrow \mathrm{C}_{3} \mathrm{H}_{5}^{+}+\mathrm{CH}_{3}, \quad m / z=41, \\
& \mathrm{C}_{4} \mathrm{H}_{8}^{+} \rightarrow \mathrm{C}_{2} \mathrm{H}_{3}+\mathrm{C}_{2} \mathrm{H}_{5}^{+}, \quad m / z=29, \\
& \mathrm{C}_{4} \mathrm{H}_{8}^{+} \rightarrow \mathrm{C}_{4} \mathrm{H}_{7}^{+}+\mathrm{H}, \quad m / z=55, \\
& \mathrm{C}_{4} \mathrm{H}_{8}^{+} \rightarrow \mathrm{C}_{2} \mathrm{H}_{6}^{+}+\mathrm{C}_{2} \mathrm{H}_{2}, \quad m / z=30 .
\end{aligned}
$$

$\mathrm{H}$ elimination from the central $\mathrm{CH}_{2}$ group of $\mathrm{C}_{4} \mathrm{H}_{8}^{+}$(1), $\mathrm{CH}_{3} \mathrm{CH}_{2} \mathrm{CHCH}_{2}^{+}$, gives $\mathrm{C}_{4} \mathrm{H}_{7}^{+}, \mathrm{CH}_{3} \mathrm{CHCHCH}_{2}^{+}$, with the energy loss of $33.8 \mathrm{kcal} / \mathrm{mol}$ and without an exit barrier. Similarly, $\mathrm{C}_{4} \mathrm{H}_{8}^{+}$(1) can lose the terminal $\mathrm{CH}_{3}$ group producing allyl radical cation $\mathrm{C}_{3} \mathrm{H}_{5}^{+}$endothermic by $37.9 \mathrm{kcal} / \mathrm{mol}$. The elimination of $\mathrm{C}_{2} \mathrm{H}_{3}$ with the formation of $\mathrm{C}_{2} \mathrm{H}_{5}^{+}$is much less favorable and requires $62.9 \mathrm{kcal} / \mathrm{mol}$. Splitting the terminal $\mathrm{CH}_{2}$ group as a neutral species or a cation exhibits prohibitively high endothermicities of 106.9 and $111.1 \mathrm{kcal} / \mathrm{mol}$, respectively, and is not likely to occur. The pathway to the $\mathrm{C}_{2} \mathrm{H}_{6}^{+}+\mathrm{C}_{2} \mathrm{H}_{2}$ products, endothermic by $78.3 \mathrm{kcal} / \mathrm{mol}$, involves flipping over the terminal $\mathrm{C}_{2} \mathrm{H}_{3}$ group with the formation of an intermediate in which $\mathrm{C}_{2} \mathrm{H}_{2}$ and $\mathrm{C}_{2} \mathrm{H}_{5}$ fragments are connected via a bridging proton, which eventually

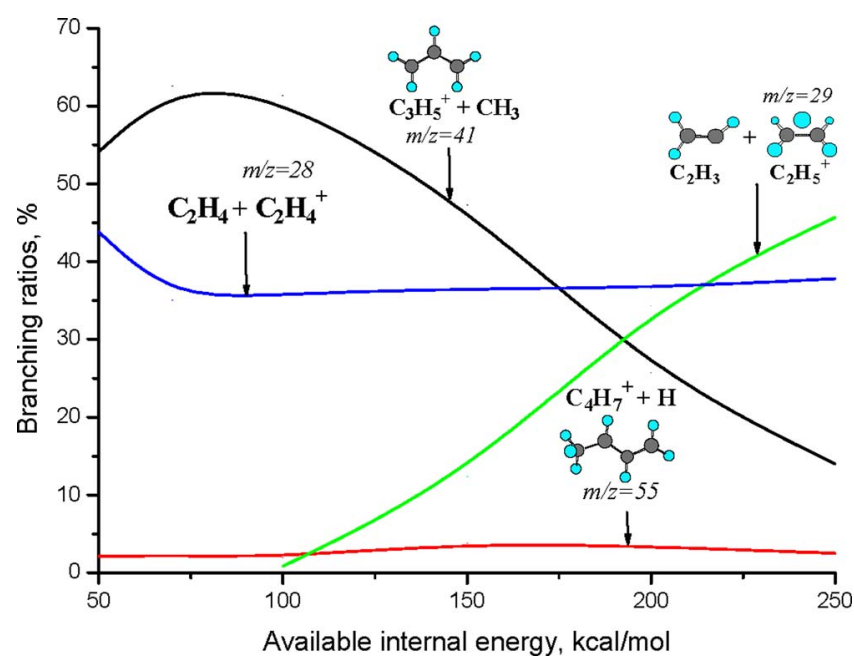

FIG. 15. (Color online) Calculated branching ratios in dissociation of $\mathrm{C}_{4} \mathrm{H}_{8}^{+}$ (2).

moves to the $\mathrm{CH}_{2}$ group of $\mathrm{C}_{2} \mathrm{H}_{5}$ to form $\mathrm{C}_{2} \mathrm{H}_{6}^{+}$. Finally, $\mathrm{C}_{4} \mathrm{H}_{8}^{+}$(1) can rearrange to $\mathrm{C}_{4} \mathrm{H}_{8}^{+}(2)$, which is described as a $\mathrm{C}_{2} \mathrm{H}_{4} \cdots \mathrm{C}_{2} \mathrm{H}_{4}^{+}$complex, by rotation around the central $\mathrm{C}-\mathrm{C}$ bond followed by $\mathrm{H}$ migration from $\mathrm{CH}_{3}$ to $\mathrm{CH}$. The highest barrier on this pathway, $29.2 \mathrm{kcal} / \mathrm{mol}$, is for the hydrogen shift. $\mathrm{C}_{4} \mathrm{H}_{8}^{+}$(2), residing $17.5 \mathrm{kcal} / \mathrm{mol}$ above $\mathrm{C}_{4} \mathrm{H}_{8}^{+}(1)$, easily decomposes to $\mathrm{C}_{2} \mathrm{H}_{4}^{+}+\mathrm{C}_{2} \mathrm{H}_{4}$ with the energy loss of $24.1 \mathrm{kcal} / \mathrm{mol}$. According to RRKM calculations, dissociation of $\mathrm{C}_{4} \mathrm{H}_{8}^{+}$(2) at relatively low internal energies is dominated by $\mathrm{C}_{3} \mathrm{H}_{5}^{+}+\mathrm{CH}_{3}$ and $\mathrm{C}_{2} \mathrm{H}_{4}^{+}+\mathrm{C}_{2} \mathrm{H}_{4}$, whereas at higher energies the $\mathrm{C}_{2} \mathrm{H}_{5}^{+}+\mathrm{C}_{2} \mathrm{H}_{3}$ channel becomes important (Fig. 15). The contribution of the $\mathrm{H}$ elimination channel, $\mathrm{C}_{4} \mathrm{H}_{7}^{+}$ $+\mathrm{H}$, remains rather small, $2 \%-3 \%$, in the entire internal energy range considered.

Ethylene cation can be also produced in secondary decomposition of another important primary dissociation product, $\mathrm{C}_{3} \mathrm{H}_{4} \mathrm{O}^{+}\left(\mathrm{CH}_{2} \mathrm{CH}_{2} \mathrm{CO}^{+}\right)$, by elimination of the $\mathrm{CO}$ group endothermic by $24.5 \mathrm{kcal} / \mathrm{mol}$ (Fig. 10). Interestingly, both for $\mathrm{C}_{3} \mathrm{H}_{4} \mathrm{O}^{+}$and $\mathrm{C}_{4} \mathrm{H}_{8}^{+}$(2), likely dissociation products are $\mathrm{C}_{2} \mathrm{H}_{4}^{+}+\mathrm{C}_{2} \mathrm{H}_{4}+\mathrm{CO}$, but the eliminations of $\mathrm{CO}$ and $\mathrm{C}_{2} \mathrm{H}_{4}$ take place in a different order (see Fig. 10). Another feasible decomposition channel of $\mathrm{CH}_{2} \mathrm{CH}_{2} \mathrm{CO}^{+}$is $\mathrm{H}$ elimination from the central $\mathrm{CH}_{2}$ group to produce $\mathrm{C}_{3} \mathrm{H}_{3} \mathrm{O}^{+}\left(\mathrm{CH}_{2} \mathrm{CHCO}^{+}\right)$ with endothermicity of $32.1 \mathrm{kcal} / \mathrm{mol}$. The $\mathrm{C}_{5} \mathrm{H}_{7} \mathrm{O}^{+}(4)$ primary product $\left(\mathrm{CH}_{3} \mathrm{CH}_{2} \mathrm{CHCHCO}^{+}\right)$, which may be formed if primary decomposition starts from the open-chain $i 6$ intermediate, is most likely to dissociate to $\mathrm{C}_{3} \mathrm{H}_{5}^{+}$ $+\mathrm{H}_{2} \mathrm{C}=\mathrm{C}=\mathrm{O}$ [Fig. 14(b)]. The pathway to these products involves isomerization to $\mathrm{C}_{5} \mathrm{H}_{7} \mathrm{O}^{+}\left(\mathrm{CH}_{2} \mathrm{CHCH}_{2} \mathrm{CH}_{2} \mathrm{CO}^{+}\right)$ via a barrier of $48.0 \mathrm{kcal} / \mathrm{mol}$ by two hydrogen shifts a $\mathrm{CH}_{3} \mathrm{CHCH}_{2} \mathrm{CH}_{2} \mathrm{CO}^{+}$intermediate formed after the first $\mathrm{H}$ migration appeared to be metastable, as it exists only at the B3LYP level, but disappears at G3. Next, $\mathrm{CH}_{2} \mathrm{CHCH}_{2} \mathrm{CH}_{2} \mathrm{CO}^{+}$decomposes without an exit barrier to form allyl cation and $\mathrm{H}_{2} \mathrm{C}=\mathrm{C}=\mathrm{O}$. Overall, $55.3 \mathrm{kcal} / \mathrm{mol}$ are required to form these products from $\mathrm{C}_{5} \mathrm{H}_{7} \mathrm{O}^{+}$(4). The other dissociation channels, such as $\mathrm{H}$ and $\mathrm{CH}_{3}$ elimination, are much less favorable. $\mathrm{C}_{3} \mathrm{H}_{5} \mathrm{O}^{+}$is likely to decompose to $\mathrm{C}_{2} \mathrm{H}_{5}^{+}+\mathrm{CO}$ with endothermicity of $38.8 \mathrm{kcal} / \mathrm{mol}$ [Fig. 
$10(\mathrm{~b})] . \mathrm{C}_{3} \mathrm{H}_{3} \mathrm{O}^{+}$is more stable with respect to secondary decomposition and needs $56.3 \mathrm{kcal} / \mathrm{mol}$ of internal energy to dissociate to $\mathrm{C}_{2} \mathrm{H}_{3}^{+}+\mathrm{CO}$ [Fig. $\left.10(\mathrm{c})\right]$.

We can see that the secondary dissociation channels can account for the $m / z=55\left(\mathrm{C}_{4} \mathrm{H}_{7}^{+}\right), 41\left(\mathrm{C}_{3} \mathrm{H}_{5}^{+}\right), 28\left(\mathrm{C}_{2} \mathrm{H}_{4}^{+}\right)$, and $29\left(\mathrm{C}_{2} \mathrm{H}_{5}^{+}\right)$peaks. On the other hand, the nonappearance of the $m / z=83$ and 57 peaks in the spectra is likely due to instability of $\mathrm{C}_{5} \mathrm{H}_{7} \mathrm{O}^{+}$and $\mathrm{C}_{3} \mathrm{H}_{5} \mathrm{O}^{+}$with respect to their decomposition to $\mathrm{C}_{3} \mathrm{H}_{5}^{+}+\mathrm{H}_{2} \mathrm{C}=\mathrm{C}=\mathrm{O}$ and $\mathrm{C}_{2} \mathrm{H}_{5}^{+}+\mathrm{CO}$, respectively, which means that these primary products, if formed, possess internal energies of at least 55.3 and $38.8 \mathrm{kcal} / \mathrm{mol}$, respectively.

\section{E. Dissociation of the $\mathrm{C}_{5} \mathrm{H}_{8} \mathrm{O}^{++}$dication}

A main drawback of the dissociation scheme originated from $\mathrm{C}_{5} \mathrm{H}_{8} \mathrm{O}^{+}$is that it cannot explain the production of $\mathrm{H}^{+}$ and $\mathrm{CH}_{3}^{+}$and that the signal of $m / z=42$ may also be due to the production of $\mathrm{C}_{5} \mathrm{H}_{8} \mathrm{O}^{++}$. In general, the appearance of a proton peak in mass spectra is a sign of the production of ions with a charge higher than 1 . For monocations, dissociation channels giving $\mathrm{H}^{+}$are energetically unfavorable as compared to other channels due to the very high ionization energy of a hydrogen atom, $13.6 \mathrm{eV}$. The vertical double ionization potential of cyclopentanone is computed to $26.58 \mathrm{eV}$. However, the cyclic structure of the dication is not a local minimum and, upon geometry optimization, undergoes spontaneous ring opening accompanied by $\mathrm{H}$ migration to the terminal $\mathrm{CH}_{2}$ group to form $\mathrm{CH}_{3} \mathrm{CHCH}_{2} \mathrm{CH}_{2} \mathrm{CO}^{++}$in singlet electronic state. Considering this $\mathrm{C}_{5} \mathrm{H}_{8} \mathrm{O}^{++}$isomer, the adiabatic double ionization energy of cyclopentanone is $21.63 \mathrm{eV}$. In Fig. 16, we present the dissociation mechanism of $\mathrm{C}_{5} \mathrm{H}_{8} \mathrm{O}^{++}$; the main dissociation channels are shown in the following:

$$
\begin{aligned}
& \mathrm{C}_{5} \mathrm{H}_{8} \mathrm{O}^{++} \rightarrow \mathrm{C}_{4} \mathrm{H}_{5} \mathrm{O}^{+}+\mathrm{CH}_{3}^{+}, \quad m / z=69 / 15, \\
& \mathrm{C}_{5} \mathrm{H}_{8} \mathrm{O}^{++} \rightarrow \mathrm{C}_{3} \mathrm{H}_{5} \mathrm{O}^{+}+\mathrm{C}_{2} \mathrm{H}_{3}^{+}, \quad m / z=57 / 27, \\
& \mathrm{C}_{5} \mathrm{H}_{8} \mathrm{O}^{++} \rightarrow \mathrm{C}_{3} \mathrm{H}_{3} \mathrm{O}^{+}+\mathrm{C}_{2} \mathrm{H}_{5}, \quad m / z=55 / 29, \\
& \mathrm{C}_{5} \mathrm{H}_{8} \mathrm{O}^{++} \rightarrow \mathrm{C}_{4} \mathrm{H}_{7}^{+}+\mathrm{HCC}^{+}, \quad m / z=55 / 29, \\
& \mathrm{C}_{5} \mathrm{H}_{8} \mathrm{O}^{++} \rightarrow \mathrm{C}_{5} \mathrm{H}_{7} \mathrm{O}^{+}+\mathrm{H}^{+}, \quad m / z=83 / 1 .
\end{aligned}
$$

The most favorable channel for $\mathrm{CH}_{3}^{+}$elimination involves the 1,2-H shift from $\mathrm{CH}_{2}$ to $\mathrm{CH}$, which is followed by 1,2migration of the $\mathrm{CH}_{3}$ group after the transition state, to form a branched $\mathrm{CH}_{3} \mathrm{C}(\mathrm{H})\left(\mathrm{CH}_{2}\right) \mathrm{CH}_{2} \mathrm{CO}^{+}$intermediate residing $9.8 \mathrm{kcal} / \mathrm{mol}$ higher in energy than the initial dication. The barrier for this process is calculated to be $23.0 \mathrm{kcal} / \mathrm{mol}$. The branched intermediate loses $\mathrm{CH}_{3}^{+}$via a barrier of $33.6 \mathrm{kcal} / \mathrm{mol}$ relative to the $\mathrm{CH}_{3} \mathrm{CHCH}_{2} \mathrm{CH}_{2} \mathrm{CO}^{++}$reactant producing $\mathrm{C}_{4} \mathrm{H}_{5} \mathrm{O}^{+}(2), \mathrm{CH}_{2} \mathrm{CHCH}_{2} \mathrm{CO}^{+}$, with overall exothermicity of $23.9 \mathrm{kcal} / \mathrm{mol}$. The $\mathrm{C}_{4} \mathrm{H}_{5} \mathrm{O}^{+}$(2) cation is relatively unstable and needs only $24.2 \mathrm{kcal} / \mathrm{mol}$ of internal energy to give the $\mathrm{C}_{3} \mathrm{H}_{5}^{+}+\mathrm{CO}$ products. Other pathways leading to the $\mathrm{CH}_{3}^{+}$elimination involve the formation of a fivemember $\mathrm{C}_{4} \mathrm{O}$ ring from the initial dication, with the $\mathrm{CH}_{3}$ group attached, followed by its loss either immediately or
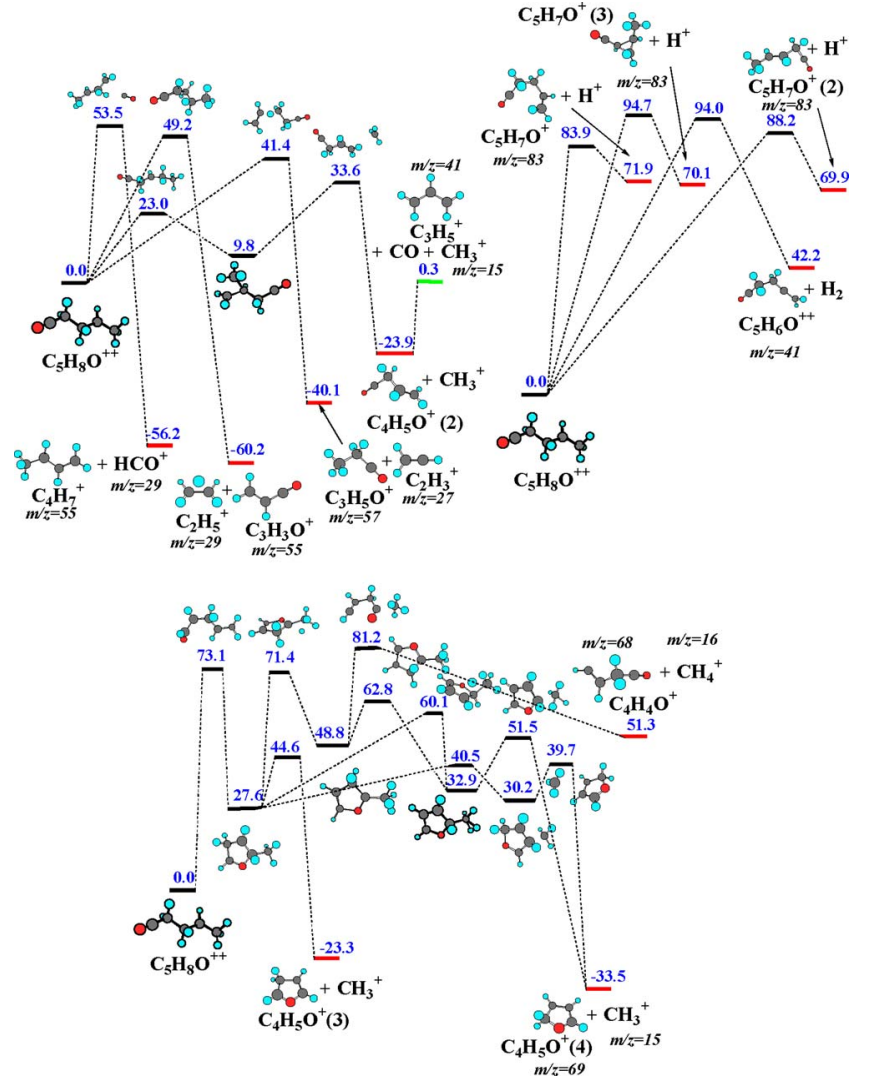

FIG. 16. (Color online) Dissociation mechanism of $\mathrm{C}_{5} \mathrm{H}_{8} \mathrm{O}^{++}$.

after a number of hydrogen shifts and producing various cyclic $\mathrm{C}_{4} \mathrm{H}_{5} \mathrm{O}^{+}$isomers. However, these channels are controlled by the initial ring closure step, which exhibits a high barrier of $73.1 \mathrm{kcal} / \mathrm{mol}$, effectively rendering this mechanism noncompetitive.

The $\mathrm{C}_{5} \mathrm{H}_{8} \mathrm{O}^{++}$dication can also decompose in one step to $\mathrm{C}_{3} \mathrm{H}_{5} \mathrm{O}^{+}+\mathrm{C}_{2} \mathrm{H}_{3}^{+}, \mathrm{C}_{3} \mathrm{H}_{3} \mathrm{O}^{+}+\mathrm{C}_{2} \mathrm{H}_{5}^{+}$, and $\mathrm{C}_{4} \mathrm{H}_{7}^{+}+\mathrm{HCO}^{+}$via barriers of $41.4,49.2$, and $53.5 \mathrm{kcal} / \mathrm{mol}$, respectively. Interestingly, in all of these processes, a bond cleavage goes together with a hydrogen atom migration. $\mathrm{H}^{+}$elimination can take place from different positions in $\mathrm{C}_{5} \mathrm{H}_{8} \mathrm{O}^{++}$to form $\mathrm{C}_{5} \mathrm{H}_{7} \mathrm{O}^{+}$ $\left(\mathrm{CH}_{2} \mathrm{CHCH}_{2} \mathrm{CH}_{2} \mathrm{CO}^{+}\right), \mathrm{C}_{5} \mathrm{H}_{7} \mathrm{O}^{+}$(2) $\left(\mathrm{CH}_{3} \mathrm{CHCHCH}_{2} \mathrm{CO}^{+}\right)$, and three-member ring $\mathrm{C}_{5} \mathrm{H}_{7} \mathrm{O}^{+}(3)$ overcoming rather high barriers of $83.9,88.2$, and $94.7 \mathrm{kcal} / \mathrm{mol}$, respectively. Finally, splitting a neutral $\mathrm{H}_{2}$ molecule gives a $\mathrm{C}_{5} \mathrm{H}_{6} \mathrm{O}^{++}$dication $\left(\mathrm{CH}_{2} \mathrm{CCH}_{2} \mathrm{CH}_{2} \mathrm{CO}^{++}\right)$, but the barrier is also high, $94.0 \mathrm{kcal} / \mathrm{mol}$. The calculated branching ratios are shown in Fig. 17. The $\mathrm{C}_{4} \mathrm{H}_{5} \mathrm{O}^{+}(2)+\mathrm{CH}_{3}^{+}$channel appears to be most important up to internal energies higher than $200 \mathrm{kcal} / \mathrm{mol}$. As mentioned above, $\mathrm{C}_{4} \mathrm{H}_{5} \mathrm{O}^{+}(2)$ is likely to decompose to $\mathrm{C}_{3} \mathrm{H}_{5}^{+}+\mathrm{CO}$ if it possesses internal energy higher than $24.2 \mathrm{kcal} / \mathrm{mol}$. The second significant product channel is $\mathrm{C}_{3} \mathrm{H}_{5} \mathrm{O}^{+}+\mathrm{C}_{2} \mathrm{H}_{3}^{+}$with its branching ratio peaking at $\sim 225 \mathrm{kcal} / \mathrm{mol}$. The $\mathrm{C}_{3} \mathrm{H}_{5} \mathrm{O}^{+}$product will not survive and will further dissociate to $\mathrm{C}_{2} \mathrm{H}_{5}^{+}+\mathrm{CO}$ if its internal energy is higher than $38.8 \mathrm{kcal} / \mathrm{mol}$. The third channel, which becomes the most important above $200 \mathrm{kcal} / \mathrm{mol}$ is $\mathrm{C}_{4} \mathrm{H}_{7}^{+}$ $+\mathrm{HCO}^{+}$. Finally, the $\mathrm{H}^{+}$elimination starts to play some noticeable role only at high internal energies. Interestingly, the $\mathrm{C}_{3} \mathrm{H}_{3} \mathrm{O}^{+}+\mathrm{C}_{2} \mathrm{H}_{5}^{+}$channel does not exhibit any significant 


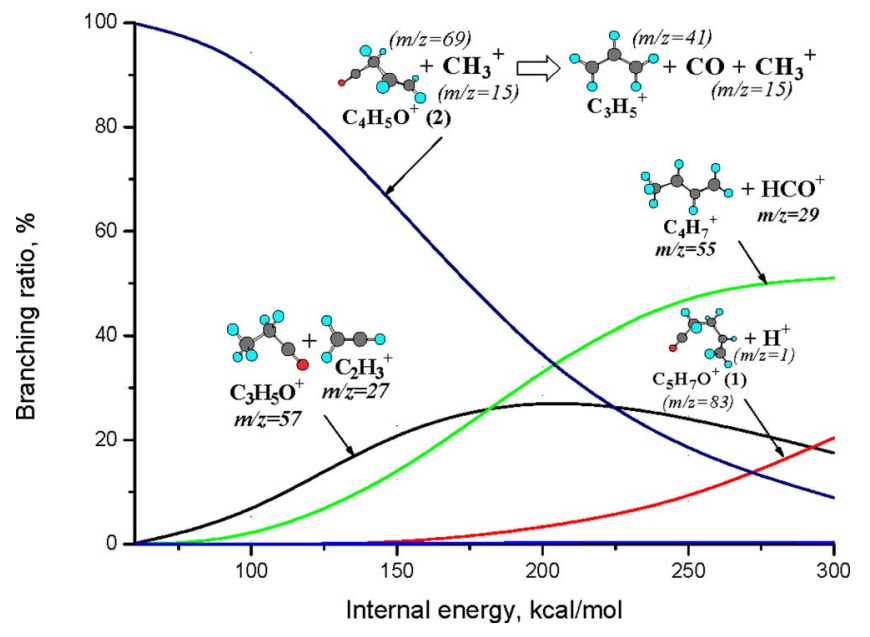

FIG. 17. (Color online) Calculated branching ratios in dissociation of $\mathrm{C}_{5} \mathrm{H}_{8} \mathrm{O}^{++}$.

yield despite of a relatively low barrier of $49.2 \mathrm{kcal} / \mathrm{mol}$, which is caused by a very tight character of the corresponding transition state resulting in a low rate constant.

Considering the dication dissociation mechanism, we can now account for the $m / z=15$ peak $\left(\mathrm{CH}_{3}^{+}\right)$and the group of peaks down to $m / z=12$, which can be produced by sequential $\mathrm{H}$ losses from $\mathrm{CH}_{3}^{+}$to $\mathrm{C}^{+}, m / z=41\left(\mathrm{C}_{3} \mathrm{H}_{5}^{+}\right.$formed by secondary decomposition of $\mathrm{C}_{4} \mathrm{H}_{5} \mathrm{O}^{+}$or $\left.\mathrm{C}_{5} \mathrm{H}_{7} \mathrm{O}^{+}\right), m / z=27$ and $26\left(\mathrm{C}_{2} \mathrm{H}_{3}^{+}\right.$and $\mathrm{C}_{2} \mathrm{H}_{2}^{+}$produced by $\mathrm{H}$ loss from the former), $m / z=29\left(\mathrm{HCO}^{+}\right.$and $\mathrm{C}_{2} \mathrm{H}_{5}^{+}$from secondary dissociation of $\mathrm{C}_{3} \mathrm{H}_{5} \mathrm{O}^{+}, m / z=55\left(\mathrm{C}_{4} \mathrm{H}_{7}^{+}\right)$, and $m / z=1\left(\mathrm{H}^{+}\right)$. Table I summarizes our assignment of the origin of various peaks observed the mass spectra.

Only few spectral features remain unexplained at this stage, a small peak at $m / z=32$, a relatively high intensity of the proton peak, and a significantly higher intensity of $\mathrm{m} / \mathrm{z}$ $=39$ compared to that of $m / z=40$. The 32 peak might be due to methanol cation, $\mathrm{CH}_{3} \mathrm{OH}^{+}$, however, despite a careful search we failed to find any pathway to this product either on the monocation or dication PES. We speculate that this peak could originate from small $\mathrm{O}_{2}$ impurity, if a small amount of oxygen molecules present undergo multiphoton ionization in intense laser field.

The $\mathrm{H}^{+}$peak growing with the laser field intensity might be due to decomposition of cyclopentanone trication. Indeed, our $a b$ initio/RRKM calculations for $\mathrm{C}_{5} \mathrm{H}_{8} \mathrm{O}^{+++}$show that its major dissociation channels are expected to be $\mathrm{C}_{3} \mathrm{H}_{4} \mathrm{O}^{++}$ $+\mathrm{C}_{2} \mathrm{H}_{4}^{+}$and $\mathrm{C}_{5} \mathrm{H}_{7} \mathrm{O}^{++}+\mathrm{H}^{+}$, which require barriers of only 3.1 and $25.1 \mathrm{kcal} / \mathrm{mol}$, respectively. However, since no evidence of the trication formation is found either in experiment or in theoretical calculations of ionization rate constants, we do not consider the $\mathrm{C}_{5} \mathrm{H}_{8} \mathrm{O}^{+++} \mathrm{PES}$ in detail here. Another possibility to produce $\mathrm{H}^{+}$, which should increase with the laser field intensity, is further ionization of the primary cationic products to form dications, which should be able to eliminate $\mathrm{H}^{+}$more easily than their single-charged counterparts. This hypothesis is also supported by the absence of the $\mathrm{m} / z=83$ $\left(\mathrm{C}_{5} \mathrm{H}_{7} \mathrm{O}^{+}\right)$and $41.5\left(\mathrm{C}_{5} \mathrm{H}_{7} \mathrm{O}^{++}\right)$peaks in the spectra.

Concerning the series of peaks at $m / z=42-39, \mathrm{C}_{3} \mathrm{H}_{6}^{+}$ (42) is a possible minor primary product [Fig. 12(b)], $\mathrm{C}_{3} \mathrm{H}_{5}^{+}$
TABLE I. Assignment of the observed peaks in the experimental mass spectra due to ionization/dissociation of cyclopentanone in a femtosecond laser field.

\begin{tabular}{|c|c|c|}
\hline$m / z$ & Species & Origin \\
\hline 84 & $\mathrm{C}_{5} \mathrm{H}_{8} \mathrm{O}^{+}$ & Parent monocation \\
\hline \multirow[t]{2}{*}{56} & $\mathrm{C}_{4} \mathrm{H}_{8}^{+}$ & Primary dissociation of $\mathrm{C}_{5} \mathrm{H}_{8} \mathrm{O}^{+}$ \\
\hline & $\mathrm{C}_{3} \mathrm{H}_{4} \mathrm{O}^{+}$ & Primary dissociation of $\mathrm{C}_{5} \mathrm{H}_{8} \mathrm{O}^{+}$ \\
\hline \multirow[t]{3}{*}{55} & $\mathrm{C}_{3} \mathrm{H}_{3} \mathrm{O}^{+}$ & $\begin{array}{l}\text { Primary dissociation of } \mathrm{C}_{5} \mathrm{H}_{8} \mathrm{O}^{+} \text {initiated from } \\
\mathrm{CH}_{3} \mathrm{CH}_{2} \mathrm{COCHCH}_{2} \text { (i6) }\end{array}$ \\
\hline & & Secondary dissociation of $\mathrm{C}_{3} \mathrm{H}_{4} \mathrm{O}^{+}$ \\
\hline & $\mathrm{C}_{4} \mathrm{H}_{7}^{+}$ & Secondary dissociation of $\mathrm{C}_{4} \mathrm{H}_{8}^{+}$ \\
\hline \multirow[t]{2}{*}{42} & $\mathrm{C}_{5} \mathrm{H}_{8} \mathrm{O}^{++}$ & Parent dication \\
\hline & $\mathrm{C}_{3} \mathrm{H}_{6}^{+}$ & Primary dissociation of $\mathrm{C}_{5} \mathrm{H}_{8} \mathrm{O}^{+}$initiated from i6 \\
\hline \multirow[t]{4}{*}{41} & $\mathrm{C}_{3} \mathrm{H}_{5}^{+}$ & Secondary dissociation of $\mathrm{C}_{4} \mathrm{H}_{8}^{+}$ \\
\hline & & $\mathrm{H}$ loss from $\mathrm{C}_{3} \mathrm{H}_{6}^{+}$ \\
\hline & & $\begin{array}{l}\text { Secondary dissociation of } \mathrm{C}_{4} \mathrm{H}_{5} \mathrm{O}^{+} \text {, a major product of } \\
\text { dication dissociation }\end{array}$ \\
\hline & & $\begin{array}{l}\text { Secondary dissociation of } \mathrm{C}_{5} \mathrm{H}_{7} \mathrm{O}^{+} \text {, a minor product of } \\
\text { dication dissociation }\end{array}$ \\
\hline 40 & $\mathrm{C}_{3} \mathrm{H}_{4}^{+}$ & $\mathrm{H}$ loss from $\mathrm{C}_{3} \mathrm{H}_{5}^{+}$ \\
\hline 39 & $\mathrm{C}_{3} \mathrm{H}_{3}^{+}$ & $\mathrm{H}$ loss from $\mathrm{C}_{3} \mathrm{H}_{4}^{+}$ \\
\hline 32 & $\mathrm{O}_{2}^{+}$ & Ionization of $\mathrm{O}_{2}$ impurity \\
\hline \multirow[t]{3}{*}{29} & $\mathrm{C}_{2} \mathrm{H}_{5}^{+}$ & Secondary dissociation of $\mathrm{C}_{4} \mathrm{H}_{8}^{+}$ \\
\hline & & $\begin{array}{l}\text { Secondary dissociation of } \mathrm{C}_{3} \mathrm{H}_{5} \mathrm{O}^{+} \text {, a minor product from } \\
\text { i6 or dication }\end{array}$ \\
\hline & $\mathrm{HCO}^{+}$ & Primary dissociation of dication \\
\hline \multirow[t]{6}{*}{28} & $\mathrm{C}_{2} \mathrm{H}_{4}^{+}$ & Secondary dissociation of $\mathrm{C}_{4} \mathrm{H}_{8}^{+}$ \\
\hline & & Secondary dissociation of $\mathrm{C}_{3} \mathrm{H}_{4} \mathrm{O}^{+}$ \\
\hline & & $\mathrm{H}$ loss from $\mathrm{C}_{2} \mathrm{H}_{5}^{+}$ \\
\hline & & $\begin{array}{l}\text { Primary dissociation of } \mathrm{C}_{5} \mathrm{H}_{8} \mathrm{O}^{+++} \text {(if the trication can be } \\
\text { produced) }\end{array}$ \\
\hline & $\mathrm{C}_{3} \mathrm{H}_{4} \mathrm{O}^{++}$ & $\begin{array}{l}\text { Primary dissociation of } \mathrm{C}_{5} \mathrm{H}_{8} \mathrm{O}^{+++} \text {(if the trication can be } \\
\text { produced) }\end{array}$ \\
\hline & $\mathrm{C}_{5} \mathrm{H}_{8} \mathrm{O}^{+++}$ & Parent trication (unlikely to be produced) \\
\hline \multirow[t]{3}{*}{27} & $\mathrm{C}_{2} \mathrm{H}_{3}^{+}$ & Dissociation of $\mathrm{C}_{3} \mathrm{H}_{3} \mathrm{O}^{+}$ \\
\hline & & Primary dissociation of dication \\
\hline & & $\mathrm{H}$ loss from $\mathrm{C}_{2} \mathrm{H}_{4}^{+}$ \\
\hline 26 & $\mathrm{C}_{2} \mathrm{H}_{2}^{+}$ & $\mathrm{H}$ loss from $\mathrm{C}_{2} \mathrm{H}_{3}^{+}$ \\
\hline 15 & $\mathrm{CH}_{3}^{+}$ & Primary dissociation of dication \\
\hline 14 & $\mathrm{CH}_{2}^{+}$ & $\mathrm{H}$ loss from $\mathrm{CH}_{3}^{+}$ \\
\hline 13 & $\mathrm{CH}^{+}$ & $\mathrm{H}$ loss from $\mathrm{CH}_{2}^{+}$ \\
\hline 12 & $\mathrm{C}^{+}$ & $\mathrm{H}$ loss from $\mathrm{CH}^{+}$ \\
\hline \multirow[t]{3}{*}{1} & $\mathrm{H}^{+}$ & Primary dissociation of dication (a minor product) \\
\hline & & $\begin{array}{l}\text { Primary dissociation of } \mathrm{C}_{5} \mathrm{H}_{8} \mathrm{O}^{+++} \text {(if the trication can be } \\
\text { produced) }\end{array}$ \\
\hline & & $\begin{array}{l}\text { Dissociation of dications produced by ionizing primary } \\
\text { products }\end{array}$ \\
\hline
\end{tabular}

(41) can be formed by $\mathrm{H}$ loss from $\mathrm{C}_{3} \mathrm{H}_{6}^{+}$and also is likely to be produced from $\mathrm{C}_{4} \mathrm{H}_{8}^{+}, \mathrm{C}_{5} \mathrm{H}_{7} \mathrm{O}^{+}$, and from the $\mathrm{C}_{4} \mathrm{H}_{5} \mathrm{O}^{+}(2)$ primary product of dication dissociation. Next, $\mathrm{C}_{3} \mathrm{H}_{4}^{+}(40)$ and $\mathrm{C}_{3} \mathrm{H}_{3}^{+}$(39) can be produced by sequential $\mathrm{H}$ losses from $\mathrm{C}_{3} \mathrm{H}_{5}^{+}$. The fact that the 39 peak is significantly more intense than 40 can be attributed to different stabilities of the $\mathrm{C}_{3} \mathrm{H}_{n}^{+}$ ions with respect to the hydrogen atom elimination. In particular, the endothermicities of the $\mathrm{C}_{3} \mathrm{H}_{5}^{+} \rightarrow \mathrm{C}_{3} \mathrm{H}_{4}^{+}+\mathrm{H}, \mathrm{C}_{3} \mathrm{H}_{4}^{+}$ $\rightarrow \mathrm{C}_{3} \mathrm{H}_{3}^{+}+\mathrm{H}$, and $\mathrm{C}_{3} \mathrm{H}_{3}^{+} \rightarrow \mathrm{C}_{3} \mathrm{H}_{2}^{+}+\mathrm{H}$ reactions are calculated to be $91.7,38.7$, and $122.4 \mathrm{kcal} / \mathrm{mol}$, respectively, which means that $\mathrm{C}_{3} \mathrm{H}_{3}^{+}$is the most stable ion in the series, whereas $\mathrm{C}_{3} \mathrm{H}_{4}^{+}$is the least stable one and thus is most likely to decompose. The higher stability of $\mathrm{C}_{3} \mathrm{H}_{3}^{+}$owes to aromatic stabilization of its cyclic structure. 
The present results on cyclopentanone ionization/ dissociation in intense femtosecond laser field in general show similarity with the previous experimental studies of laser induced ionization/dissociation of this molecule. ${ }^{10,12}$ Meanwhile, due to much higher laser intensity, significantly deeper dissociation patterns have been observed, which owe to higher available internal energies due to absorption of a large number photons. Several mass spectral features can be attributed to the formation of cyclopentanone dication followed by its decomposition. It should be also noted that the experimental measurements and theoretical calculations here are highly complementary to each other. Experimental mass spectra does not allow unique assignment of the observed peaks to particular fragments because different species can have the same mass (e.g., $\mathrm{C}_{4} \mathrm{H}_{8}^{+}$and $\mathrm{C}_{3} \mathrm{H}_{4} \mathrm{O}^{+}$) and because dications can be potentially formed with the same $\mathrm{m} / z$ ratio as monocations, such as $\mathrm{C}_{5} \mathrm{H}_{8} \mathrm{O}^{++}$and $\mathrm{C}_{3} \mathrm{H}_{6}^{+}$. The experimental mass spectra also cannot distinguish between different isomers of the same species. On the other hand, theoretical $a b$ initio/RRKM calculations assume statistical character of dissociation after intramolecular vibrational redistribution is completed the assumption which may not be valid at high available internal energies. Also, under conditions of multiphoton ionization/dissociation, unlike in photodissociation upon absorption of a single photon of a fixed wavelength, the parent ions and their primary fragments may acquire different amounts of internal energy, which complicates the theoretical analysis. In addition, field assisted dissociation may also play a significant role. Nevertheless, the combined experimental/theoretical study has allowed us to unravel the ionization/dissociation mechanism of cyclopentanone at least qualitatively and to positively assign all observed peaks in the mass spectra.

\section{CONCLUSIONS}

In conclusion, in this paper, we studied the ionization processes of cyclopentanone under $90 \mathrm{fs}$ intense laser field irradiation for 394 or $788 \mathrm{~nm}$ wavelengths and the intensities varying from $3 \times 10^{13}$ to $4 \times 10^{14} \mathrm{~W} / \mathrm{cm}^{2}$. Rescattering processes are important only under very strong laser field conditions, typically above $10^{14} \mathrm{~W} / \mathrm{cm}^{2}$; however, in our work, the laser intensity covers $10^{13}-10^{14} \mathrm{~W} / \mathrm{cm}^{2}$ and the field may not be high enough for the rescattering contribution to become important. More experimental and theoretical work needs to be done in future to address the role of rescattering at a stronger laser field regime.

The laser dependence of parent ion and the main fragment ions for both wavelengths has been demonstrated. We have calculated the ionization rate constants by using ADK, Keldysh, and KFR theories based on a hydrogenlike atom. We believe that the generalized KFR theory, which is based on the original KFR theory combined with MO theory and the $\mathrm{BO}$ approximation, is the best choice for calculating the ionization rate constants for cyclopentanone. According to the calculated results, in our laser-intensity range, the doubly charged parent ion may not be found due to much lower rate of second ionization process compared with first ionization. Furthermore, we compare the experimental ion yields with theoretical results. In the lower intensity region, experimental results for both wavelength cases show a good agreement with theoretical ones. However, in the higher intensity range, there exists a difference between experimental and calculated results for the $788 \mathrm{~nm}$ case. An important feature of the mass spectra obtained from the high power laser ionization/ dissociation of molecules is that due to the non-negligible contribution from the tunneling ionization, the internal energy deposited in the parent ion forms a distribution function which is to be determined. It should be noted that the detailed analysis of the Keldysh theory can provide the information of the most probable multiphoton process involved in high-power laser ionization of molecules. In other words, it is possible to estimate the distribution function of internal energy $k_{N} / \Sigma_{N>N_{0}}^{\infty} k_{N}$ with $N_{0}=\left(I_{0}+U\right) / \omega$ from Eq. (3.5), which is a function of photon numbers $N$

$$
\begin{aligned}
k_{N}= & \sum_{N} 2 \pi S^{2} \sum_{j, j^{\prime}=1}^{N_{e}} c_{j} c_{j^{\prime}}^{*} \int \frac{d^{3} p}{(2 \pi)^{3}} \hat{\chi}_{j}(\vec{p}) \hat{\chi}_{j}^{*}(\vec{p}) \\
& \times\left(\frac{p^{2}}{2 m_{e}}+I_{e}\right)^{2}\left|J_{N}\left(\frac{e \vec{F} \cdot \vec{p}}{m_{e} \omega^{2}}, \frac{U}{2 \omega}\right)\right|^{2} \\
& \times \cos \left(\vec{p} \cdot\left(\vec{R}_{j}-\vec{R}_{j^{\prime}}\right)\right) \delta\left(I_{0}+U+\frac{p^{2}}{2 m_{e}}-N \omega\right) .
\end{aligned}
$$

Furthermore, in the case of high-power laser ionization/ dissociation, there might be some contribution from the socalled FAD of the parent ion which will further complicate the decomposition processes of the parent ion. From the theoretical point of view, FAD processes will need to be addressed by calculations of PES and reaction dynamics in the presence of a strong laser field. At this point, a qualitative understanding of the femtosecond ionization/dissociation mechanisms of cyclopentanone has been achieved by using the RRKM theory based on the ab initio surfaces.

\section{ACKNOWLEDGMENTS}

Support by the National Science Foundation of China (NSFC) under Grant Nos. 10534010 and 10374036 are acknowledged. A.M.M. thanks the US Department of EnergyBasic Energy Sciences (Grant No. DE-FG02-04ER15570) for partial support of this work.

${ }^{1}$ H. Harada, S. Shimizu, T. Yatsuhashi, S. Sakabe, Y. Izawa, and N. Nakashima, Chem. Phys. Lett. 342, 563 (2001).

${ }^{2}$ L. Hongtao, Y. Zheng, G. Zhen, and T. Zichao, J. Chem. Phys. 126, 044316 (2007).

${ }^{3}$ K. W. D. Ledingham, R. P. Singhal, D. J. Smith, T. McCanny, P. Graham, H. S. Kilic, W. X. Peng, S. L. Wang, A. J. Langley, P. F. Taday, and C. Kosmidis, J. Phys. Chem. A 102, 3002 (1998).

${ }^{4}$ R. Ma, C. Wu, N. Xu, J. Huang, H. Yang, and Q. Gong, Chem. Phys. Lett. 415, 58 (2005).

${ }^{5}$ N. Nakashima, S. Shimizu, T. Yatsuhashi, S. Sakabe, and Y. Izawa, J. Photochem. Photobiol. C 1, 131 (2000).

${ }^{6}$ S. Shimizu, V. Zhakhovskii, F. Sato, S. Okihara, S. Sakabe, K. Nishihara, Y. Izawa, T. Yatsuhashi, and N. Nakashima, J. Chem. Phys. 117, 3180 (2002).

${ }^{7}$ M. Tanaka, M. Murakami, T. Yatsuhashi, and N. Nakashima, J. Chem. Phys. 127, 104314 (2007).

${ }^{8}$ S. A. Trushin, W. Fuß, and W. E. Schmid, J. Phys. B 37, 3987 (2004).

${ }^{9}$ D. Wu, Q. Q. Wang, X. H. Cheng, M. X. Jin, X. Y. Li, Z. Hu, and D. Ding, J. Phys. Chem. A 111, 9494 (2007). 
${ }^{10}$ C. Kosmidis, J. G. Philis, and P. Tzallas, Phys. Chem. Chem. Phys. 1, 2945 (1999).

${ }^{11}$ K. Furuya, E. Yamamoto, Y. Jinbou, and T. Ogawa, J. Electron Spectrosc. Relat. Phenom. 73, 59 (1995).

${ }^{12}$ M. Baba, H. Sinohara, N. Nishi, and N. Hirota, Chem. Phys. 83, 221 (1984)

${ }^{13}$ T. J. Cornish and T. Baer, J. Am. Chem. Soc. 109, 6915 (1987).

${ }^{14}$ C. Kosmidis, G. Boulakis, A. Bolovinos, P. Tsekeris, and P. Brint, J. Mol. Struct. 266, 133 (1992).

${ }^{15}$ E. W. G. Diau, C. Kotting, T. I. Solling, and A. H. Zewail, ChemPhysChem 3, 57 (2002).

${ }^{16}$ E. W. G. Diau, C. Kotting, and A. H. Zewail, ChemPhysChem 2, 273 (2001)

${ }^{17}$ C. Y. Wu, Y. J. Xiong, J. X. Wang, and F. A. Kong, Chin. Chem. Lett. 11, 545 (2000).

${ }^{18}$ Z. Hu, M. X. Jin, H. Liu, J. Yang, and D. Ding, J. Atom. Mol. Phys. 21, 567 (2004) (in Chinese)

${ }^{19}$ C. Kosmidis, P. Tzallas, K. W. D. Ledingham, T. McCanny, R. P. Singhal, P. F. Taday, and A. J. Langley, J. Phys. Chem. A 103, 6950 (1999).

${ }^{20}$ G. Bieri, L. Åsbrink, and W. von Niessen, J. Electron Spectrosc. Relat. Phenom. 27, 129 (1982).

${ }^{21}$ M. V. Ammosov, N. B. Delone, and V. P. Krainov, Sov. Phys. JETP 64, 1191 (1986)

${ }^{22}$ T. Brabec, M. Cote, P. Boulanger, and L. Ramunno, Phys. Rev. Lett. 95, 073001 (2005).

${ }^{23}$ X. M. Tong and C. D. Lin, J. Phys. B 38, 2593 (2005).

${ }^{24}$ L. V. Keldysh, Sov. Phys. JETP 20, 1307 (1965).

${ }^{25}$ K. Mishima, K. Nagaya, M. Hayashi, and S. H. Lin, Phys. Rev. A 70, 063414 (2004).

${ }^{26}$ K. Nagaya, H. Mineo, K. Mishima, A. A. Villaeys, M. Hayashi, and S. H. Lin, Phys. Rev. A 75, 013402 (2007).

${ }^{27}$ T. K. Kjeldsen, C. Z. Bisgaard, L. B. Madsen, and H. Stapelfeldt, Phys. Rev. A 68, 063407 (2003).

${ }^{28}$ V. I. Usachenko and S.-I. Chu, Phys. Rev. A 71, 063410 (2005).
${ }^{29}$ H. Mineo, S. D. Chao, K. Nagaya, K. Mishima, M. Hayashi, and S. H. Lin, Chem. Phys. Lett. 439, 224 (2007).

${ }^{30}$ F. H. M. Faisal, J. Phys. B 6, L89 (1973).

${ }^{31}$ H. R. Reiss, Phys. Rev. A 22, 1786 (1980).

${ }^{32}$ K. Mishima, M. Hayashi, J. Yi, S. H. Lin, H. L. Selzle, and E. W. Schlag, Phys. Rev. A 66, 033401 (2002)

${ }^{33}$ H. Mineo, K. Nagaya, M. Hayashi, and S. H. Lin, J. Phys. B 40, 2435 (2007).

${ }^{34}$ M. Sharifi, F. Kong, S. L. Chin, H. Mineo, Y. Dyakov, A. M. Mebel, S. D. Chao, M. Hayashi, and S. H. Lin, J. Phys. Chem. A 111, 9405 (2007).

${ }^{35}$ N. Nakashima, T. Yatsuhashi, M. Murakami, R. Mizoguchi, and Y. Shimada, Advances in Multi-photon Processes and Spectroscopy (World Scientific, Singapore, 2006).

${ }^{36}$ P. J. Linstrom and W. G. Mallard, NIST Chemistry WebBook, (NIST Standard Reference Database National Institute of Standards and Technology, Gaithersburg, 2005), Vol. 69.

${ }^{37}$ Y. Teranishi, M. Hayashi, F. Kong, S. L. Chin, S. D. Chao, H. Mineo, and S. H. Lin, Mol. Phys. 106, 333 (2008).

${ }^{38}$ X. P. Tang, S. F. Wang, M. E. Elshakre, L. R. Gao, Y. L. Wang, H. F. Wang, and F. A. Kong, J. Phys. Chem. A 107, 13 (2003).

${ }^{39}$ A. D. Becke, J. Chem. Phys. 98, 5648 (1993); C. Lee, W. Yang, and R. G. Parr, Phys. Rev. B 37, 785 (1988).

${ }^{40}$ A. G. Baboul, L. A. Curtiss, P. C. Redfern, and K. Raghavachari, J. Chem. Phys. 110, 7650 (1999); L. A. Curtiss, K. Raghavachari, P. C. Redfern, A. G. Baboul, and J. A. Pople, Chem. Phys. Lett. 314, 101 (1999).

${ }^{41}$ G. W. T. M. J. Frisch, H. B. Schlegel, G. E. Scuseria et al., GAUSSIAN 03, Gaussian, Inc., Pittsburgh, 2003.

${ }^{42}$ MOLPRO, a package of $a b$ initio programs designed by H.-J. Werner, P. J. Knowles, J. Almlöf et al.

${ }^{43}$ H.-J. Werner and P. J. Knowles, J. Chem. Phys. 89, 5803 (1988); P. J. Knowles and H.-J. Werner, Chem. Phys. Lett. 145, 514 (1988).

${ }^{44}$ T. H. Dunning, Jr., J. Chem. Phys. 90, 1007 (1989).

${ }^{45}$ S. Pedersen, J. L. Herek, and A. H. Zewail, Science 266, 1359 (1994). 